UNIVERSIDADE DE SÃO PAULO

FACULDADE DE CIÊNCIAS FARMACÊUTICAS DE RIBEIRÃO PRETO

\title{
Avaliação de rotas metabólicas como mecanismo de ação da atividade tripanocida de Lignano-Lactonas
}

Tese de Doutorado apresentada ao Programa de PósGraduação em Biociências Aplicadas à Farmácia para obtenção do Título de Doutor em Biociências Aplicadas à Farmácia.

Área de Concentração: Biociências Aplicadas à Farmácia

Orientada: Juliana Saraiva

Orientador: Prof. Dr. Sérgio de Albuquerque 


\section{FOLHA DE APROVAÇÃO}

Juliana Saraiva

Avaliação de rotas metabólicas como mecanismo de ação da atividade tripanocida de

Lignano-Lactonas

Tese de doutorado apresentada ao Programa de PósGraduação em Biociências Aplicadas à Farmácia para obtenção do Título de Doutor em Biociências Aplicadas à Farmácia.

Área de Concentração: Biociências Aplicadas à Farmácia

Orientador: Prof. Dr. Sérgio de Albuquerque

Aprovado em:

Banca Examinadora

Prof. Dr.

Instituição: Assinatura:

Prof. Dr.

Instituição: Assinatura:

Prof. Dr.

Instituição: Assinatura:

Prof. Dr.

Instituição: Assinatura:

Prof. Dr.

Instituição: Assinatura: 
Dedico este trabalho...

A minha família em especial aos meus pais

Jacomo Saraiva e Ieda de Barros Saraiva, com amor por estarem sempre presentes em minha vida dando-me todo apoio e carinho.

Também a Deus por tornar tudo possível 


\section{AGRADECIMEENTOS}

Ao meu orientador e amigo Prof. Dr. Sérgio de Albuquerque, pelos ensinamentos, dedicação, confiança e apoio.

Ao Prof. Dr. Carlos Curti do laboratório de Bioquímica da FCFRP-USP, pela valiosa colaboração, atenção e apoio durante a realização dos experimentos realizados em seu laboratório.

Ao Prof. Dr. Jairo K. Bastos do laboratório de Farmacognosia da FCFRPUSP, pelos ensinamentos, incentivo e correções.

A Profa. Dra. Rosangela da Silva e ao Prof. Dr. Marcio L. A e Silva do Núcleo de Pesquisa em Ciências Exatas e Tecnológicas da Universidade de Franca pela síntese das substâncias e correções relativas à parte química.

A Profa. Dra. Alicia Gómez-Barrio do laboratório de Parasilologia da Universidade Complutense de Madrid por me receber em seu laboratório dandome toda atenção, apoio e incentivo.

Ao Prof. Dr. Jorge Perez Serrano do laboratório de Parasilologia e Microbiologia da Universidade de Alcalá, pela colaboração em me receber em seu Caboratório para realização da microscopia eletrônica. 
Ao Prof. Dr. Sérgio Akira do laboratório de Bioquímica Clínica da FCFRPUSP, pelos ensinamentos e apoio durante a realização dos experimentos de respiração celular.

Ao Prof. Dr. Richard Charles Garratt do laboratório de cristalografia de Proteínas e Biologia Estrutural do IFSC-USP por disponibilizar seu laboratório para realização dos ensaios sobre a enzima superóxido dismutase.

Ao Prof. Dr. Carlos Henrique Tomich de Paula da Silva do laboratório de Química Farmacêutica da FCFRP-USP, pela colaboração e ensinamentos relativos às analises virtuais.

A Profa. Dra. Mônica Tallarico Pupo pela realização das analises sobre a enzima GAPDH.

A Profa. Dra. Juliana M. Marchetti pelo incentivo e colaboração nas perspectivas deste trabalho.

Aos Professores do Laboratório de Parasitologia Prof. Dr. José Clóvis do Prado Júnior e Profa. Dra. Ana Amélia Carraro. A6rahão por estarem sempre prontos a ajudar.

Ao pos graduando José Fernando Ruggiero Bachega pelo apoio para realização das análises no laboratório de cristalografia de Proteínas e Biologia Estrutural do IFSC-USP. 
Ao pos graduando Vinicius Barreto da Silva pelo auxilio durante a realização das análises virtuais.

A Amélia Regina de Albuquerque pelo apoio, incentivo e amizade.

A todos do Laboratório de Parasitologia (FCFRP-USP; UCM), Bioquímica (FCFRP-USP) e Bioquímica clínica (FCFRP-USP), e pela colaboração e amizade, em especial aos pos graduandos Dani, Vivi, Valéria, Cláudia, Daniel, Celeste, Miriam e Rory.

Ao Georgius, Toninha e Miriam do Laboratório de parasitologia pela colaboração.

A Fundação de amparo à pesquisa do Estado de São Paulo (FAPESP) pelo auxilio financeiro.

Ao José Eduardo do Val primeiro pela compreensão, mas também por todo incentivo, apoio e amor demonstrados neste período.

Ao Seu Sylvio e a Dona Elvira pelo apoio e incentivo durante a realização deste trabalho.

A todos da Universidade Paranaense, em especial a Rosilamar e Carlos Eduardo por minha formação acadêmica. 
A toda minha família, meus pais Jacomo e Ieda, minha Irmã Luciana, meu cunhado Marcelo, meus sobrinhos Bruno e Georgia Maria e a todos meus tios e primos, por todo carinho, apoio e estímulo.

OBRIGADA! 


\section{RESUMO}

SARAIVA, J. Avaliação de rotas metabólicas como mecanismo de ação da atividade tripanocida de Lignano-Lactonas. 2007. 151f. Tese (Doutorado). Faculdade de Ciências Farmacêuticas de Ribeirão Preto - Universidade de São Paulo, Ribeirão Preto, 2007

Neste trabalho o metilpluviatolido (1), o matairesinol (7), a hinoquinina (11), a cubebina (17) e seus respectivos derivados, providos de algumas modificações estruturais foram submetidos a testes in vitro para a determinação da atividade citotoxica e tripanocida. As substâncias não apresentaram atividade citotoxica significativa para a linhagem celular utilizada (LLC-MK $\mathrm{M}_{2}$ ). Nos ensaios tripanocida in vitro o dimetoximorelensin (8) e 11 foram as substâncias que determinaram as maiores atividades tripanocida sobre as varias formas e cepas de T. cruzi utilizadas e juntamente com a cubebina foram submetidas os ensaios in vivo. As substâncias determinaram alterações significativas no curso da infecção chagásica experimental. No entanto apenas a 8 apresentou efeito semelhante ao do benzonidazol para ambas as cepas, sendo a cepa BOL em relação a cepa Y mais resistente as substâncias 11 e 17. Algumas rotas metabólicas foram avaliadas como mecanismo de ação das substâncias. As substâncias não apresentaram atividade inibitória sobre a enzima gliceraldeído-3-fosfato desidrogenase (GAPDH) de Trypanosoma cruzi, não induziram a produção de $\mathrm{H}_{2} \mathrm{O}_{2}$ e outros peróxidos, bem como não induziram a produção de óxido nítrico, tendo algumas inibindo esta produção. No entanto, apresentaram efeito inibitório sobre a respiração celular e efeito inibitório sobre a enzima ferro superóxido dismutase (Fe-SOD) de Trypanosoma cruzi. Adicionalmente foi demonstrado que em sistema livre de células as substâncias não apresentam atividade scavenger de radicais livres e que o tratamento com a substancia 8 , avaliado por microscopia eletrônica, provoca alterações nucleares nas formas epimastigotas do parasita, sugerindo que a atividade tripanocida desta substancia envolva a inibição da síntese de DNA e RNA. Dessa forma, podemos concluir que a atividade tripanocida das varias lignano-lactonas avaliadas é promissora e que a produção de $\mathrm{H}_{2} \mathrm{O}_{2}$ e outros peróxidos, atividade inibitória sobre a enzima gliceraldeído-3-fosfato desidrogenase (GAPDH) de Trypanosoma cruzi, bem como a capacidade de indução de óxido nítrico pelos derivados bioativos são mecanismos que parecem não estar envolvidos na atividade tripanocida das substâncias. Além disso, que o efeito inibitório sobre a respiração celular parece contribuir para a atividade tripanocida e pode estar envolvido no mecanismo de citotoxicidade destas substâncias. Ainda, que o efeito inibitório sobre a enzima ferro superóxido dismutase (FeSOD) de Trypanosoma cruzi parece ser um dos principais mecanismos envolvidos na atividade tripanocida das substâncias.

Palavras chave: 1- Trypanosoma cruzi, 2- lignano lactonas, 3- mecanismo de ação, 4tripanocida, 5- citotoxica 


\begin{abstract}
SARAIVA, J. Evaluation of metabolic route as trypanocidal action mechanism of Lignan-Lactones. 2007. 151f. Thesis (Doctoral). Faculdade de Ciências Farmacêuticas de Ribeirão Preto - Universidade de São Paulo, Ribeirão Preto, 2007
\end{abstract}

In this work the compounds methylpluviatolide (1), matairesinol (7), hinokinin (11), cubebin (17) and its derivatives bearing some structural modifications were submitted to in vitro trypanocidal and citotoxic assays. The compounds do not show significant citotoxicity for the LLC- $\mathrm{MK}_{2}$ cells used. In the in vitro trypanocidal assays, the compounds more active against the different strains and forms of $T$. cruzi were the dimethoxymorelensin (8) and hinokinin (11). These compounds and cubebin (17) were submitted to in vivo trypanocidal assay. The compounds display significant modifications on the experimental chagasic infection. However, for both strains, $\mathrm{Y}$ and BOL, only the 8 displayed similar effect of the benznidazole. The BOL strain was more resistant than Y strain to treatment with 11 and 17. Some metabolic routes were evaluated as compounds action mechanism. The compounds do not showed inhibitory activity under enzyme glyceraldehyde-3-phosphate dehydrogenase (GAPDH) of Trypanosoma cruzi, they do not induced the production of $\mathrm{H}_{2} \mathrm{O}_{2}$ and others peroxides and also do not induced the nitric oxide production, instead some compounds decrease this production. On the other hand, they showed inhibitory effect under the cellular respiration and the enzyme iron superoxide dismutase (Fe-SOD) of Trypanosoma cruzi. In addition, it was demonstrated that on system cells free, the compounds do not showed free radicals scavenger activity and that the treatment with the compound 8 , evaluated in electron microscopy, display nuclear alterations on epimastigotes forms, suggesting an inhibitory effect on $T$. cruzi DNA and RNA biosynthesis. In conclusion, the compounds trypanocidal activity is promising and the production of $\mathrm{H}_{2} \mathrm{O}_{2}$ and others peroxides, the activity under enzyme glyceraldehyde-3-phosphate dehydrogenase (GAPDH) of Trypanosoma cruzi, and the induction of nitric oxide production seem do not be involved in the trypanocidal and citotoxity activity of these group of compounds. The inhibitory effect under cellular respiration seems to be contributing for trypanocidal activity and may be involved on its citotoxic mechanism. Moreover, the inhibitory effect under the enzyme iron superoxide dismutase (Fe-SOD) of Trypanosoma cruzi seems to be the main mechanism involved on trypanocidal activity of these compounds.

Key words: 1- Trypanosoma cruzi, 2- lignan lactones, 3- action mechanism, 4- trypanocidal, 5- citotoxic 


\section{LISTA DE FIGURAS}

Figura 1. Distribuição Global da doença de Chagas............................... 22

Figura 2. Ciclo biológico de Trypanosoma cruzi (A); Formas evolutivas de Trypanosoma cruzi $(\mathbf{B})$.

Figura 3. Agrupamento das cepas de Trypanosoma cruzi segundo Satellite Meeting (1999)

Figura 4. Estrutura química dos fármacos nifurtimox (1) e benzonidazol (2)............ 28

Figura 5. Estrutura química da violeta de genciana................................................... 29

Figura 6. Estrutura química do álcool coniferílico..................................................... 30

Figura 7. Representação esquemática de Piper cubeba L......................................... 31

Figura 8. Processo de degradação da glicose pela via glicolítica. Hexoquinase (HK); Fosfoglucose isomerase (PGI); 6-Fosfofrutoquinase (PFK); 6Fosfofrutoquinase (PFK); Triose fosfato isomerase (TIM); Gliceraldeído 3-fosfato desidrogenase (GAPDH); 3-fosfoglicerato quinase (PGK); Glicerol 3-fosfato desidrogenase (GDH); Glicerol quinase (GK)

Figura 9. Reações antioxidantes em células de mamífero e em Trypanosoma cruzi. Enzima $\mathrm{Cu}, \mathrm{Zn}$ - superoxido dismutase (CuZn-SOD); Enzima Mnsuperoxido dismutase (Mn-SOD); Enzima Fe- superoxido dismutase (FeSOD); radical superóxido $\left(\mathrm{O}_{2}{ }^{-}\right)$peróxido de hidrogênio $\left(\mathrm{H}_{2} \mathrm{O}_{2}\right)$; enzima glutationa peroxidase (GPx); enzima tripanotiona peroxidase (TPx) glutationa oxidada (GSSH); tripanotiona oxidada $\left(\mathrm{T}(\mathrm{S})_{2}\right)$; glutationa redutase (GRd); tripanotiona redutase (TRd); glutationa reduzida (GSH); tripanotiona reduzida $\left(\mathrm{T}(\mathrm{SH})_{2}\right)$

Figura 10. Reações antioxidantes em células de mamífero e em Trypanosoma cruzi. Enzima $\mathrm{Cu}, \mathrm{Zn}$ - superoxido dismutase (CuZn-SOD); Enzima Mnsuperoxido dismutase (Mn-SOD); Enzima Fe- superoxido dismutase (FeSOD); radical superóxido $\left(\mathrm{O}_{2}{ }^{-}\right)$peróxido de hidrogênio $\left(\mathrm{H}_{2} \mathrm{O}_{2}\right)$; enzima glutationa peroxidase (GPx); enzima tripanotiona peroxidase (TPx) glutationa oxidada (GSSH); tripanotiona oxidada $\left(\mathrm{T}(\mathrm{S})_{2}\right)$; glutationa redutase (GRd); tripanotiona redutase (TRd); glutationa reduzida (GSH); tripanotiona reduzida $\left(\mathrm{T}(\mathrm{SH})_{2}\right)$ 
Figura 11. Estrutura tridimencional da enzima ferro superóxido dismutase (Fe-SOD) de T. cruzi, indicando os resíduos do canal que leva ao sítio ativo

Figura 12. Estrutura tridimencional da subunidade B8 da enzima NADH desidrogenase humana, indicando os resíduos conservados utilizados na analise.

Figura 13. Curva parasitemica de camundongos BALB/C infectados intraperitonealmente com $4 \times 10^{4}$ tripomastigotas $/ \mathrm{mL}$, das cepas $\mathrm{Y}$ (A) e Bolívia (B) de Trypanosoma cruzi e submetidos ao tratamento diário com cubebina (17), hinoquinina (11), dimetoximorelensin (8) e benzonidazol (BZN), na dosagem de $8 \mathrm{mg} / \mathrm{kg}$.

Figura 14. Porcentagem de mortalidade avaliada durante a evolução da infecção experimental em $\mathrm{BALB} / \mathrm{C}$ infectados com $4 \times 10^{4}$ tripomastigotas sangüíneas das cepas $\mathrm{Y}$ (A) e Bolívia (B) de T. cruzi, tratados com cubebina (17), hinoquinina (11), dimetoximorelensin(8) e benzonidazol $(\mathrm{BZN})$

Figura 15. Avaliação das modificações induzidas pelas substâncias na produção de peróxido de hidrogênio e de outros peróxidos pelas formas tripomastigotas da cepa Y e Bolívia de Trypanosoma cruzi. T-BOOH: hidroperóxido de t-butil; RFU: Unidade Relativa de Fluorescência.

Figura 16. Sobreposição das melhores orientações dos compostos 2, 11, 15, 16, 17 , 18, 19, 20 submetidos à simulação de docking com a enzima ferro superóxido dismutase (Fe-SOD) de T. cruzi. Em cinza- 2, em alaranjado11; em magenta- 15; em amarelo- 16; em rosa claro- 17; em azul claro18; em vermelho-19; azul escuro- 20. Os resíduos com maior potencial de interação estão indicados na figura.

Figura 17. Efeito do metilpluviatolideo e de seus derivados sobre a produção de óxido nítrico. Controle sem infecção (C); Controle infectado (Ci). $(* * * \mathrm{p}<0,001 ; * * \mathrm{p}<0,01 ; * \mathrm{p}<0,05)$

Figura 18. Efeito do matairesinol e de seus derivados sobre a produção de óxido nítrico Controle sem infecção (C); Controle infectado (Ci). (*p<0,001; $* * \mathrm{p}<0,01 ; * \mathrm{p}<0,05)$ 
Figura 19. Efeito da hinoquinina e de seus derivados sobre a produção de óxido nítrico Controle sem infecção (C); Controle infectado (Ci). (***p<0,001; $* * \mathrm{p}<0,01 ; * \mathrm{p}<0,05)$

Figura 20. Efeito da cubebina e de seus derivados sobre a produção de óxido nítrico Controle sem infecção (C); Controle infectado (Ci). (***p<0,001; $* * \mathrm{p}<0,01 ; * \mathrm{p}<0,05)$

Figura 21. Representação gráfica do percentual de atividade inibitória da (-) hinoquinina (11) e da (-)-7`-O-N,N-dimetiletilamino cubebina (20) sobre a respiração no estado 3 de $T$. cruzi $\left(1,0 \mathrm{mg}\right.$ protein), incubadas a $30^{\circ} \mathrm{C}$ com 2,5mM glutamato $+2,5 \mathrm{mM}$ malato, em tampão (125mM sacarose, $65 \mathrm{mM} \mathrm{KCl,} \mathrm{10mM} \mathrm{HEPES-KOH,} \mathrm{pH} \mathrm{7.4)} \mathrm{na} \mathrm{presença} \mathrm{de} 0,5 \mathrm{mM}$ de EGTA, $10 \mathrm{mM}$ de $\mathrm{K}_{2} \mathrm{HPO}_{4}$ e $64 \mu \mathrm{M}$ de digitonina, em um volume final de 1,8ml. O estado 3 da respiração foi iniciado por meio da adição de $1 \mu$ mol ADP.

Figura 22. Efeito inibitório das substâncias sobre a respiração no estado 3 de mitocôndrias isoladas do fígado de Hamster (1,5 mg protein), incubadas a $30^{\circ} \mathrm{C}$ com $2,5 \mathrm{mM}$ glutamato $+2,5 \mathrm{mM}$ malato, em tampão $(125 \mathrm{mM}$ sacarose, $65 \mathrm{mM} \mathrm{KCl}, 10 \mathrm{mM}$ HEPES-KOH, $\mathrm{pH}$ 7.4) na presença de 0,5mM EGTA e $10 \mathrm{mM} \mathrm{K}_{2} \mathrm{HPO}_{4}$, em um volume final de $1,8 \mathrm{ml}$. O estado 3 da respiração foi iniciado por meio da adição de $1 \mu$ mol ADP. Os números correspondentes às substâncias e os respectivos valores de $\mathrm{IC}_{50}$ estão demonstrados no gráfico.

Figura 23. Representação gráfica da avaliação da atividade seqüestradora de radical superóxido pelas substâncias.

Figura 24. Representação gráfica da atividade doadora de íons Hidrogênio ao radical DPPH das lignano-lactonas derivadas da cubebina.

Figura 25. Representação gráfica do efeito inibitório das substâncias sobre a produção de peróxido de hidrogênio 
Figura 26. Representação gráfica do percentual de atividade inibitória das lignanolactonas sobre a respiração no estado 3 de mitocôndrias isoladas do fígado de Hamster (1,5 mg protein), incubadas a $30^{\circ} \mathrm{C}$ com $2,5 \mathrm{mM}$ glutamato $+2,5 \mathrm{mM}$ malato, em tampão $(125 \mathrm{mM}$ sacarose, $65 \mathrm{mM} \mathrm{KCl}$, 10mM HEPES-KOH, pH 7.4) na presença de 0,5mM EGTA e $10 \mathrm{mM}$ $\mathrm{K}_{2} \mathrm{HPO}_{4}$, em um volume final de $1,8 \mathrm{ml}$. $\mathrm{O}$ estado 3 da respiração foi iniciado por meio da adição de $1 \mu$ mol ADP......

Figura 27. Efeito inibitório das substâncias sobre a respiração no estado 3 de mitocôndrias isoladas do fígado de Hamster (1,5mg protein), incubadas a $30^{\circ} \mathrm{C}$ com $2,5 \mathrm{mM}$ glutamato $+2,5 \mathrm{mM}$ malato, em tampão $(125 \mathrm{mM}$ sacarose, $65 \mathrm{mM} \mathrm{KCl}, 10 \mathrm{mM}$ HEPES-KOH, $\mathrm{pH}$ 7.4) na presença de 0,5mM EGTA e $10 \mathrm{mM} \mathrm{K}_{2} \mathrm{HPO}_{4}$, em um volume final de $1,8 \mathrm{ml}$. O estado 3 da respiração foi iniciado por meio da adição de 720nmol ADP. Os números correspondentes às substâncias e os respectivos valores de $\mathrm{IC}_{50}$ estão demonstrados no gráfico

Figura 28. Interação das substâncias com a atividade de NADH desidrogenase avaliada a $30^{\circ} \mathrm{C}$ com $100 \mu \mathrm{M}$ NADH como substrato, em solução tampão contendo $125 \mathrm{mM}$ sacarose, $65 \mathrm{mM} \mathrm{KCl,} \mathrm{10mM} \mathrm{Hepes-KOH,} \mathrm{pH} \mathrm{7.4,}$ $0.2 \mathrm{mM}$ EGTA e partículas submitocondriais $(10 \mu \mathrm{g}$ of protein/ $\mathrm{ml})$.....

Figura 29. Gráficos de duplo recíproco para inibição das substâncias sobre NADH desidrogenase. (०) controle; (•) presença das substâncias nas concentrações correspondentes aos valores de $\mathrm{IC}_{50}$

Figura 30. Sobreposição das melhores orientações dos compostos 3, 4, 11, 16, 17, 20 submetidos à simulação de docking com a subunidade B8 da enzima NADH desidrogenase humana. Em: azul claro- 3; rosa claro- 4; magenta11; amarelo- 16; vermelho-17; azul escuro- 20. Os resíduos com maior potencial de interação estão indicados na figura. $\mathrm{O}$ círculo alaranjado em (B) destaca a possível ligação de hidrogênio (traço alaranjado, 3,11 ) entre R89 e um dos átomos de oxigênio do anel benzodioxol da substância 11. O círculo azul em (C) destaca o contato desfavorável entre D85 e um dos anéis benzodioxol das substâncias menos ativas 
Figura 31. Alterações ultraestruturais nas formas epimastigotas de T. cruzi. acontrole após $72 \mathrm{~h}$ de cultivo, b- tratamento com $4 \mu \mathrm{M}$ de nifurtimox por $72 \mathrm{~h}$, c-i- tratamento com $96 \mu \mathrm{M}$ de dimetoximorelensin (8) por $72 \mathrm{~h}$. As setas indicam: a- núcleos arredondados com cromatina condensada localizada na periferia nuclear, vacúolos ocasionais e cinetoplasto em forma de bastão; b- vacúolos e alterações nucleares; c- grande número de vacúolos, presença de partículas densas e alterações nucleares; dalterações nucleares e partículas densas; e- numerosos vacúolos e alterações na cromatina; f: vacúolos também ao longo da menbrana e partículas densas; g- grande número de vacúolos e alterações nucleares; h- vacúolos; i- desorganização celular. Barras: $1 \mu \mathrm{m} . . . \ldots \ldots \ldots \ldots \ldots \ldots \ldots$ 


\section{LISTA DE TABELAS}

Tabela 1 - Determinação da dose das substâncias em estudo, citotóxica para 50\% das células $\left(\mathrm{CC}_{50}\right)$

Tabela 2 - Dose tripanocida efetiva para 50\% das formas tripomastigotas sanguíneas de Tripanosoma cruzi das cepas Y e Bolívia e citotoxica para 50\% das células

Tabela 3 - Comparação da atividade biológica das diferentes lignano-lactonas sintetizadas frente às formas amastigotas intracelulares da cepa $\mathrm{Y}$ de Trypanosoma cruzi.

Tabela 4 - Atividade tripanocida das substâncias 8, 11, 15, 17 e 19 sobre as formas epimastigotas da cepa CL de Trypanosoma cruzi.

Tabela 5 - $\quad$ Atividade tripanocida das substâncias 8 e 11 sobre as formas amastigotas da cepa CL de Trypanosoma cruzi.

Tabela 6 - Atividade específica e porcentagem de inibição da enzima gliceraldeído3-fosfato desidrogenase (GAPDH) de Trypanosoma cruzi.

Tabela 7 - Porcentagem de inibição da enzima ferro superóxido dismutase (Fe-SOD) de Trypanosoma cruzi.

Tabela 8 - Dose das substâncias capaz de inibir 50\% da produção de peróxido de hidrogênio 
LISTA DE ABREVIATURAS E SIGLAS

ADP

ATP

BHA

CLAE

CPRG

CuZn-SOD

DCF

DMSO

DPPH

EDTA

EROS

FAD

Fe-SOD

FHS

G3P

GPx

GRd

GSH

GSSH

$\mathrm{H}_{2}$ DCFDA

INF $\delta$

iNOS

LIT

MET adenosina difosfato

adenosina trifosfato

t-butil-4-hidroxianisol

cromatografia líquida de alta resolução

chlorophenol red b-D-galactopyranoside

enzima superoxido dismutase de cobre e zinco

diclorofluoriceina

dimetilsulfóxido

1, 1-difenil-2-picril-hidrazil

acido etilenodiaminotetracético

Espécies reativas de oxigênio

flavina adenosina dinucleotídeo

enzima superoxido dismutase de ferro-

soro humano fresco

gliceraldeido-3-fosfato

enzima glutationa peroxidase

glutationa redutase

glutationa reduzida

glutationa oxidada

2’7’-diclorodihidrofluoresceína

interferon gama

óxido nítrico sintase induzível

liver infusion triptose

microscopia eletrônica de transmissão 
Mn-SOD enzima superoxido dismutase de manganês

MTT 3-(4,5-dimethylthiazol-2-yl)-2,5-diphenyltetrazolium bromide

NADH

nicotinamina adenina dinucleotídeo

NBT

nitoblue tetrazolium

NO

óxido nítrico

NOS óxido nítrico sintase

OMS organização mundial de saúde

PBS salina fosfato tamponada

RMN ressonância magnética nuclear

$\mathbf{T}(\mathbf{S})_{2} \quad$ tripanotiona oxidada

$\mathbf{T}(\mathbf{S H})_{2} \quad$ tripanotiona reduzida

T-BOOH hidroperóxido de t-butil

TcGAPDH enzima Gliceraldeido-3-fosfato desidrogenase de T. cruzi

TNF $\alpha \quad$ fator de necrose tumoral

TPx enzima tripanotiona peroxidase

TRd tripanotiona redutase

UQ ubiroquinona 


\section{SUMÁRIO}

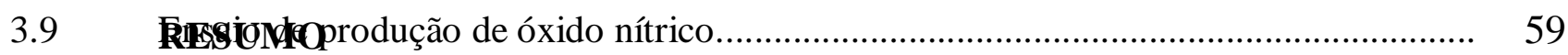

3.10 ABSTRRIA Ǵlbitória sobre a respiração de $T$. cruzi................................................... 60

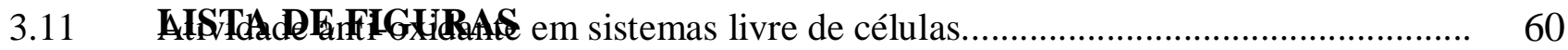

3.11.1 AISTAAdPE SeqüBETaAS a de radical superóxido, utilizando o sistema xantina/xantina GXISA DE ABREVIATURAS

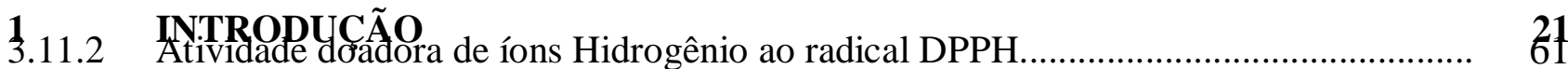

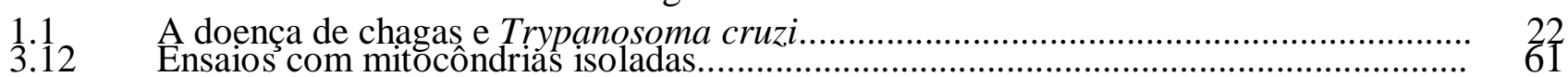

1.2 Substâncias utilizadas no controle da doença de Chagas........................................... 28

3.12.1 Isolamento das mitocôndrias....................................................................................... 61

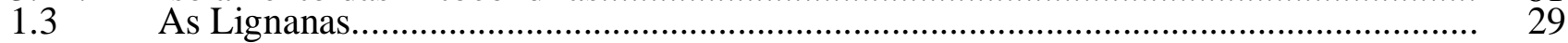

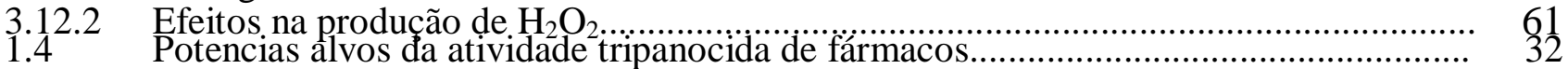

2.12.3 Efeitos nł respiração mitocondrial.................................................................. 32

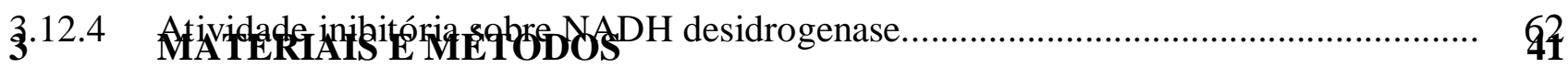

3:12.4.1 Ensaio virtyalidadsocking........................................................................................................... 43

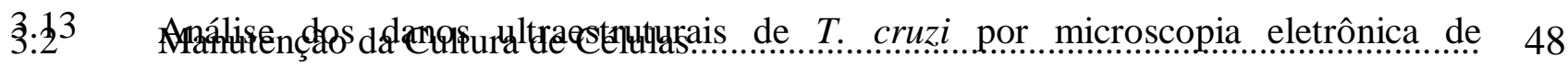

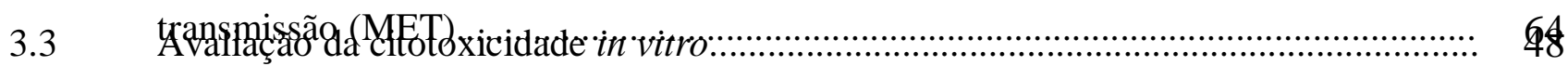

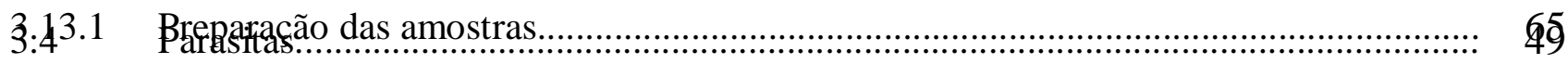

3:53.1.1 Eixąã

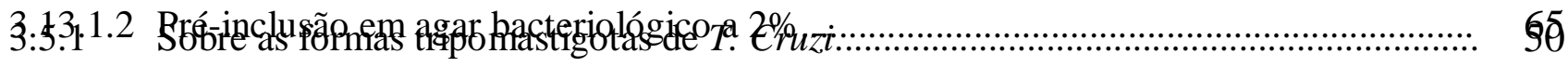

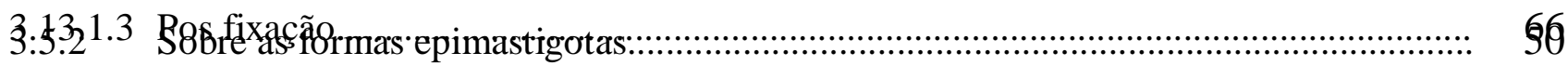

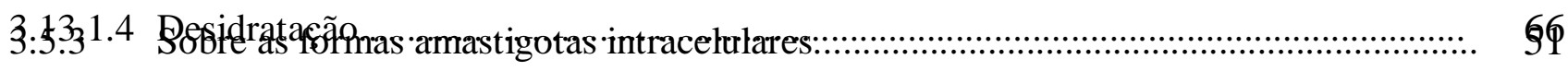

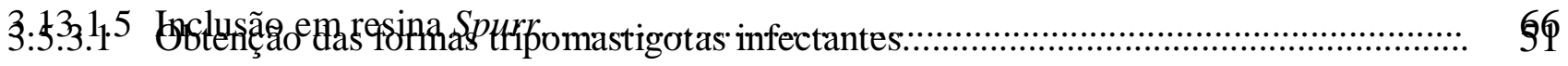

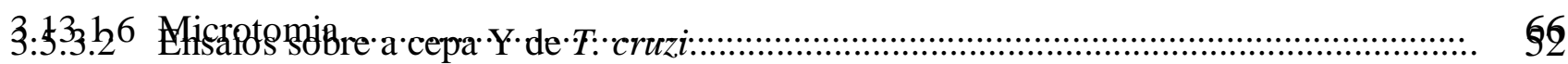

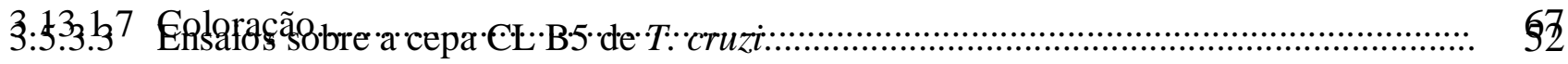

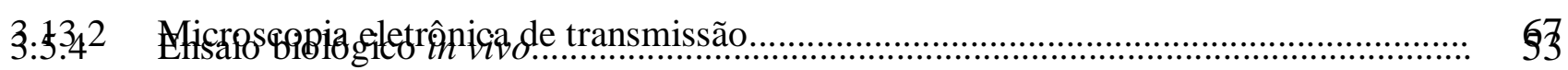

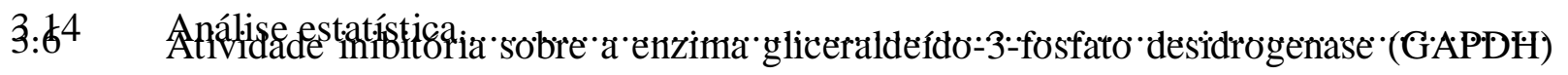

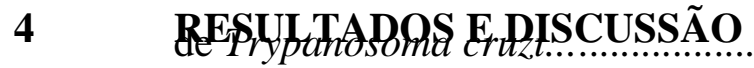

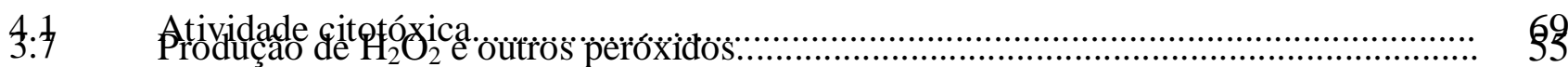

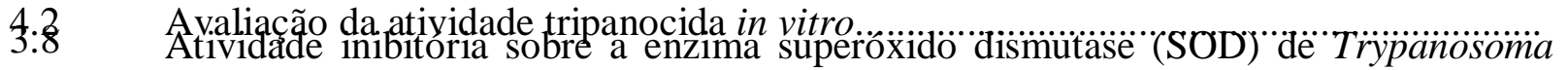

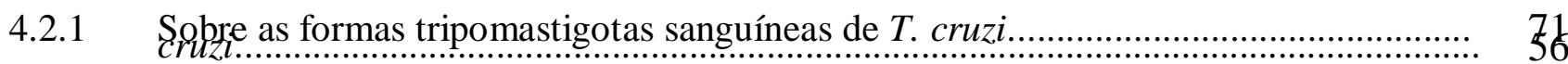

4:2.2 S.bre as formas amastigptas.intracelulares da cepa Y..................................................... $\quad$ 54 
4.2.3 Sobre as formas epimastigotas e amastigotas intracelulares da cepa CL de $T$. cruzi........

4.3 Avaliação da atividade tripanocida in vivo 78

4.4 Potenciais mecanismos da ação tripanocida avaliados.

4.4.1 Atividade inibitória sobre a enzima gliceraldeído-3-fosfato desidrogenase (GAPDH) de Trypanosoma cruzi.

4.4.2 Produção de $\mathrm{H}_{2} \mathrm{O}_{2}$ e de outros peróxidos.

4.4.3 Atividade inibitória sobre a enzima Ferro superoxido dismutase (Fe-SOD) de Trypanosoma cruzi.

4.4.4 Produção de óxido nítrico 88

4.4.5 Respiração de T. cruzi.

4.5 Atividade anti-oxidante em sistemas livre de células...

4.5.1 Atividade seqüestradora de radical superóxido, utilizando o sistema xantina/xantina oxidase

4.5.2 Atividade doadora de íons Hidrogênio ao radical DPPH.

4.6 Ensaios com mitocôndrias isoladas

4.6.1 Efeitos na produção de $\mathrm{H}_{2} \mathrm{O}_{2}$.

4.6.2 Efeitos na respiração mitocondrial.

4.6.2.1 Atividade inibitória sobre NADH desidrogenase.

4.7 Análise dos danos ultraestruturais de T. cruzi por microscopia eletrônica de transmissão (MET).

APÊNDICE A

APÊNDICE B 


\section{Introdução}

\subsection{A doença de chagas e Trypanosoma cruzi}

A doença de Chagas é considerada um problema de saúde pública, acometendo no continente americano atualmente 13 milhões de pessoas, com 3,0-3,3 milhões de casos sintomáticos e incidência de 200 mil novos casos por ano (MOREL; LAZDINS, 2003).

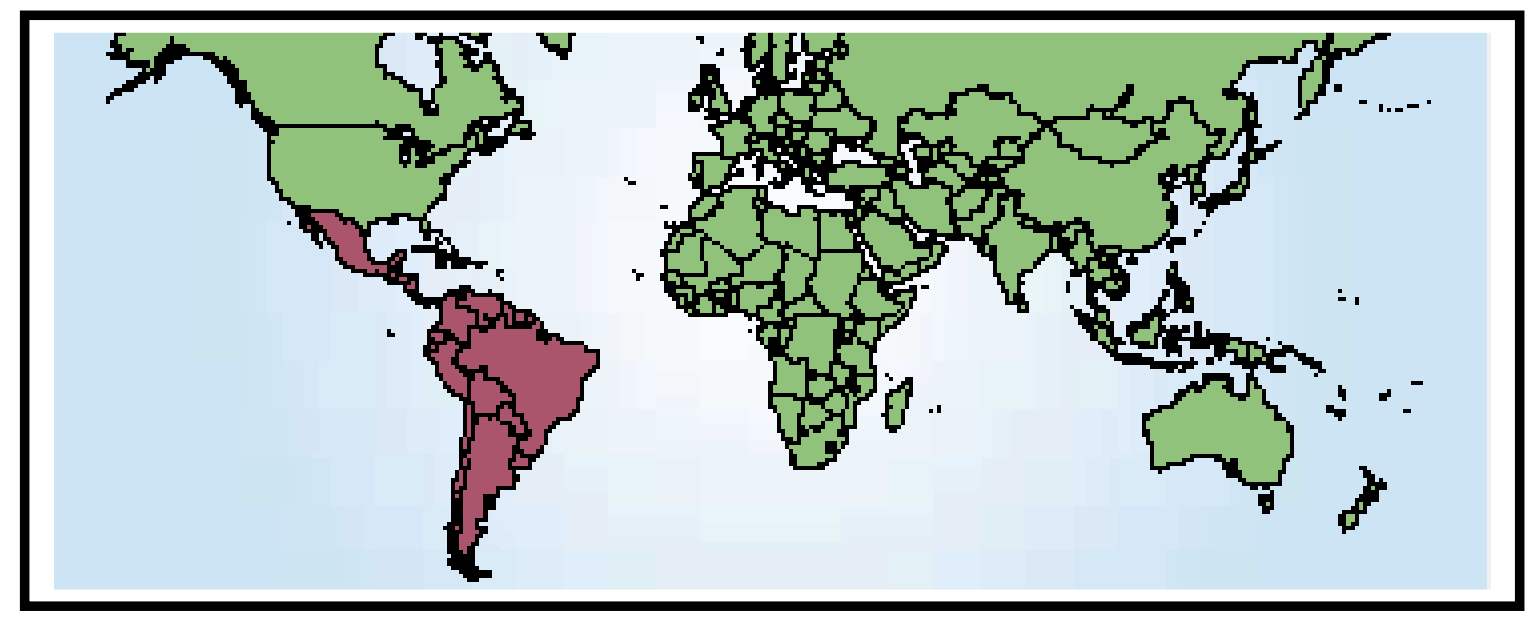

Figura 1. Distribuição Global da doença de Chagas

O agente etiológico da doença, Trypanosoma cruzi (CHAGAS, 1909) pode ser transmitido pelas fezes infectadas de triatomíneos hematófagos, por transfusão sanguínea, por via congênita, e raramente por transplante de órgão, ingestão de alimento contaminado e acidentes laboratoriais (LAMBRECHT, 1965; PRATA, 2001).

Apesar dos avanços no controle da transmissão vetorial, principal via de transmissão do parasita, algumas áreas na América Latina ainda apresentam níveis significativos de transmissão vetorial e mesmo nas áreas onde esta transmissão foi declarada nula, existe o risco de retorno em conseqüência da precoce interrupção nos programas de vigilância (DIAS; SILVEIRA; SCHOFIELD, 2002)

Além disso, o abandono progressivo do combate aos triatomíneos possibilita que eles possam novamente se adaptar as habitações humanas. Vários autores têm descrito o risco de 
surgimento da doença de Chagas endêmica na região amazônica, devido à presença de vetores infectados (LAINSON et al., 1979; D’ALESSANDRO et al., 1984; ALMEIDA, 1971; FRAIHA et al., 1995; RODRIGUES et al., 1988; NAIF et al., 1998; MILES et al., 1983; SILVEIRA; REZENDE, 1994; SILVEIRA; VINHAES, 1999; TEIXEIRA et al., 2001; LUITGARDS-MOURA et al., 2005).

A doença apresenta curso clínico variável, desenvolvendo fase aguda, indeterminada e crônica, que variam de acordo com as características do hospedeiro e da cepa infectante. A sintomatologia na doença crônica acomete aproximadamente $30 \%$ dos pacientes, sendo geralmente manifestada por comprometimento cardiovascular e/ou gastrointestinal que resultam em significativa morbidade e em aproximadamente 14 mil mortes anuais (HIGUCHI et al., 2003; WHO, 2005).

O protozoário flagelado T. cruzi pertence à ordem Kinetoplastida e a família Trypanosomatidae (HOARE, 1966). Seu ciclo biológico envolve um hospedeiro vertebrado (mamífero) e um invertebrado (vetor), podendo ser encontrado nas formas: amastigotas, nos tecidos e em cultura de células (replicação intracelular); epimastigotas, no vetor e em cultura axênica; e tripomastigotas, no sangue e em cultura de células (infectante). 


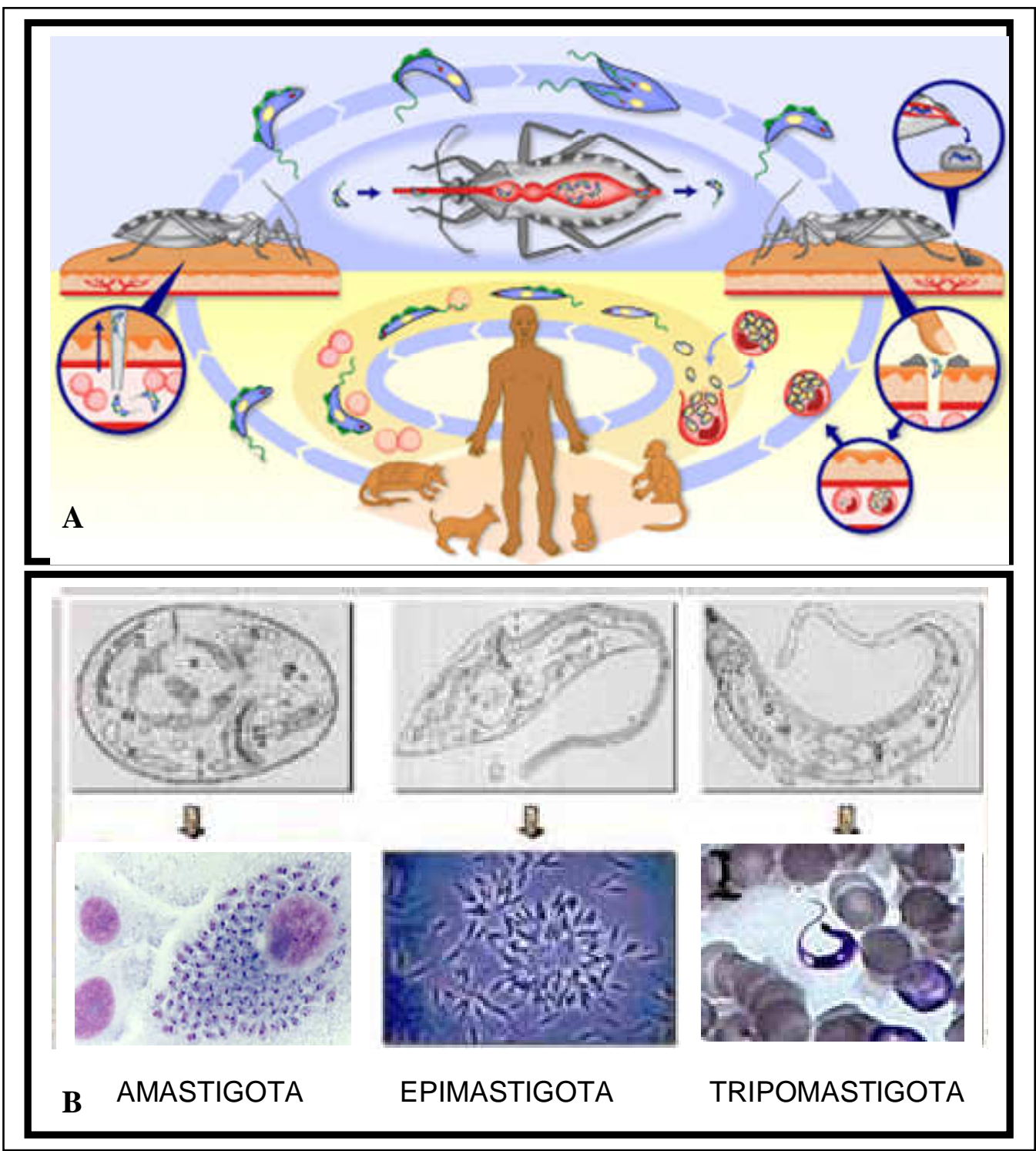

Figura 2. Ciclo biológico de Trypanosoma cruzi (A); Formas evolutivas de Trypanosoma cruzi $(\mathbf{B})$

Ainda, exibe grande diversidade fenotípica e genotípica (MILES, 1983; LUQUETTI et al., 1986 TIBAYRENC; KJELLBERG; AYALA, 1990), muitos mamíferos como reservatórios e espécies de triatomíneo como vetores (DEANE, 1961,1964; BARRETO; RIBEIRO, 1979; MAGALHÃES; ANDRADE; SHERLOCK, 1996).

As cepas de T. cruzi isoladas em diversas regiões mostram uma série de variações no que se refere à morfologia das formas tripomastigotas sangüíneas, virulência, patogenicidade, tropismo tissular e sensibilidade a quimioterápicos, entre outras (HAUSCHKA, 1949; 
TALIAFERRO; PIZZI, 1955; BRENER, 1965; BICE; ZELEDÓN, 1970; ANDRADE, 1974; ANDRADE; FIGUEIRA, 1977; ANDRADE; MAGALHÃES; PONTES, 1985).

Evidências demonstram uma variação geográfica significante na severidade e prevalência das diferentes formas clínicas da doença. Enquanto a forma digestiva da doença predomina no Chile e no Brasil central, é relativamente rara em outras áreas endêmicas e praticamente não existe na América Central (LUQUETTI et al., 1986; MACEDO et al., 2004). Estas observações sugerem que além das características próprias do hospedeiro, os fatores genéticos e biológicos do parasita podem ser importantes na fisiopatologia da doença (MILES et al., 1981; APT, et al., 1987; BRENIERE et al., 1989; ANDRADE et al., 1992; CAMPOS et al., 1999).

Vários autores evidenciaram a heterogeneidade de $T$. cruzi analisando um grande número de loci de isoenzimas (TIBAYRENC; AYALA, 1987), fragmentos do minicírculo do DNA do cinetoplasto (MOREL et al., 1980) e impressão digital do DNA nuclear (MACEDO et al., 1992). No entanto, a fim de reunir as cepas do parasita em poucos grupos algumas classificações foram propostas com base nos perfis biológico (ANDRADE, 1974), isoenzimatico (MILES et al., 1977; 1980) e no uso de marcadores derivados de sequiências gênicas não expressas que demonstrou a divisão das cepas em dois grupos classificados como linhagem 1 e 2 (SOUTO; ZINGALES, 1993; SOUTO et al., 1996).

Em vista das correlações entre estas classificações, a comunidade científica agrupou as diferentes características comportamentais do parasito em dois diferentes grupos: (SATELLITE MEETING, 1999) 
T. cruzi I $>$ Zimodema1 (MILES; LANHAM; POVOA, 1980); Linhagem 2 (SOUTO et al., 1996); Grupo 1 (TIBAYRENC, 1995); Tipo III (ANDRADE, 1974); Ribodema II/III (CLARK; PUNG, 1994)

T. cruzi II > Zimodema 2 (MILES; LANHAM; POVOA,1980); Zimodema A (ROMANHA; BRENER, 1988) Linhagem 1 (SOUTO et al., 1996) Grupo 2 ou DTU 2 (TIBAYRENC, 1995) Tipo II (ANDRADE, 1974) Ribodema I (CLARK; PUNG, 1994)

Figura 3. Agrupamento das cepas de Trypanosoma cruzi segundo Satellite Meeting (1999)

Por meio de uma investigação epidemiológica da distribuição destes dois grupos realizada por Zingales et al. (1998), o grupo I foi preferencialmente associado ao ciclo silvestre e o grupo II ao ciclo doméstico.

De forma geral, a proximidade genética entre as cepas do parasita pode estar associada a semelhanças em seu perfil biológico (ESPINOZA et al., 1998; REVOLLO et al. 1998; CAMPOS et al., 1999; MARTINÉZ-DIAZ et al., 2001; MACEDO; OLIVEIRA; PENA, 2002). Assim para avaliação de novos fármacos devem ser consideradas cepas representantes dos distintos grupos de T. cruzi.

Macedo e Pena (1998) propuseram o modelo Clonal-Histotrópico para a patogênese da doença, admitindo que as cepas de $T$. cruzi são heterogêneas, contendo clones com diversas características de tropismo tecidual e virulência. Desta forma, o conjunto de clones infectantes de um paciente é importante para determinar sua evolução clínica.

Além disso, uma das principais causas relacionadas à dificuldade de se encontrar uma substância capaz de combater o parasitismo, está diretamente ligada às características morfológicas da cepa, principalmente às diferentes populações existentes, que podem 
apresentar um tropismo tecidual diferenciado (ANDRADE, 1976; DEANE, 1979; RIBEIRO; BELDA-NETO, 1983; RIBEIRO; FERRIOLLI FILHO; BELDA NETO, 1982).

Segundo Andrade (1976), existem cepas que apresentam predominância de formas tripomastigotas sangüíneas delgadas, que por sua vez apresentam tropismo diferenciado para células do sistema fagocitário mononuclear, parasitando com maior freqüência esplenócitos, células do fígado e medula óssea e apresentando picos parasitêmicos altos e precoces. Estas, apesar de serem mais sensíveis à ação dos anticorpos circulantes, determinam na fase aguda da infecção uma taxa de mortalidade elevada na grande maioria dos animais experimentais infectados.

Entretanto existem cepas que apresentam como característica morfológica predominante a presença de formas tripomastigotas sangüíneas largas, possuindo assim, marcante tropismo para células musculares (musculatura lisa, esquelética e cardíaca) e tecido glandular (RIBEIRO; FERRIOLLI FILHO; BELDA NETO, 1982). Esse tipo de conformação morfológica confere a esta cepa maior resistência aos anticorpos circulantes e, como conseqüência, os parasitas permanecem por mais tempo na corrente circulatória determinando picos parasitêmicos tardios e infecções de duração mais prolongada. 


\subsection{Substâncias utilizadas no controle da doença de Chagas}

Desde o final de 1960 e início de 1970 apenas dois fármacos têm sido usados para o tratamento da doença de Chagas, o nifurtimox (LAMPIT ${ }^{\circledR} /$ BAYER) (BOCK; GORNERT; HABERKOM, 1969) e o benzonidazol (ROCHAGAN ${ }^{\circledR} /$ ROCHE) (RICHLE, 1973)(Figura 4).

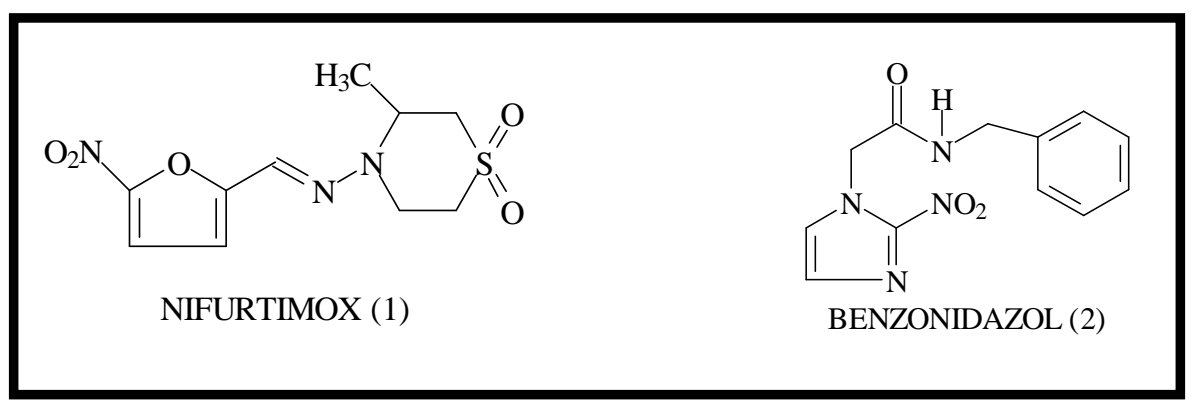

Figura 4. Estrutura química dos fármacos nifurtimox (1) e benzonidazol (2)

No Brasil, após a proibição do nifurtimox nos anos 80, o benzonidazol, comercialmente conhecido como ROCHAGAN, é o único fármaco com atividade tripanocida disponível no mercado, apesar de possuir limitada eficácia na fase crônica da infecção e de apresentar vários efeitos colaterais, tais como dermatite, depressão da medula óssea, agranulocitose e trombocitopenia (PEDROSA et al., 2001).

A situação é parecida em relação à quimioprofilaxia. A transmissão sangüínea pode ser evitada pela adição de violeta de genciana (Figura 2) ao sangue infectado (NUSSENZWEIG et al., 1953; RAMIREZ et al., 1995). No entanto esta medida profilática ainda é insuficiente, já que este corante apresenta restrições à sua utilização (THOMAS; MCPHEE, 1984), por acarretar irritação das mucosas, decréscimo do número de leucócitos, corar a pele dos pacientes transfundidos por algumas horas e apresentar potencial mutagênico e carcinogênico (DOCAMPO; MORENO, 1990). 


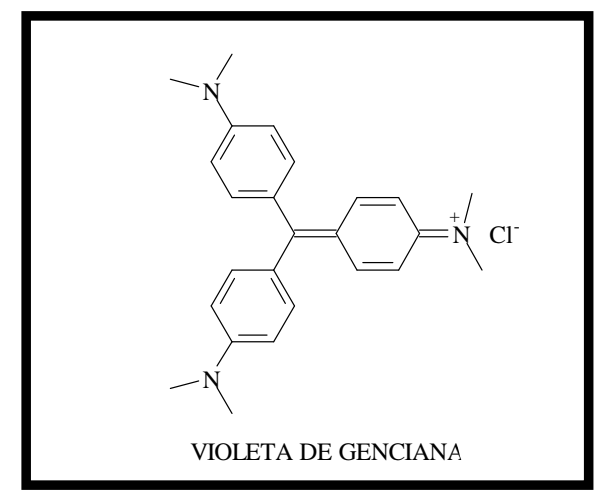

Figura 5. Estrutura química da violeta de genciana.

Em face da necessidade de novas de substâncias com atividade biológica sobre $T$. cruzi, o interesse pela pesquisa vem crescendo com o intuito de se obter compostos capazes de atuarem sobre o parasita, porém desprovidos dos efeitos colaterais. O desenvolvimento de uma quimioterapia antiparasitária pode surgir por meio de ensaios tripanocidas de produtos naturais e sintéticos, de compostos com estrutura similar a fármacos com atividade reconhecida, de ensaios com substancias já aprovadas para outras doenças ou através da determinação de alvos específicos, identificado em uma rota metabólica (COURA; de CASTRO, 2002).

\subsection{As Lignanas}

Grande importância terapêutica vem sendo atribuída a produtos de origem vegetal e a atividade tripanocida de vários princípios ativos naturais vem sendo descrita (SEPULVEDABOZA; CASSELS, 1996; BASTOS; ALBUQUERQUE; SILVA, 1999).

As lignanas são uma classe de metabólitos secundários de plantas, produzidos pela dimerização oxidativa de duas unidades fenilpropanoídicas (C6C3) de álcool coniferílico 
(Figura 6) e têm sido encontradas em mais de 70 famílias do Reino Vegetal, sendo isoladas de raízes, rizomas, folhas, sementes e frutos (SALEEM et al., 2005).

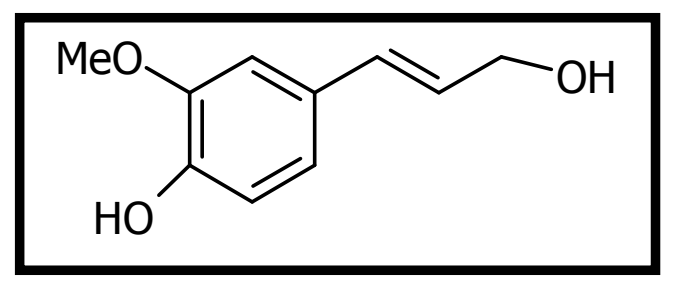

Figura 6. Estrutura química do álcool coniferílico

A literatura reporta uma série de atividades biológicas de lignanas, tais como antitumoral (AYRES; LOIKE, 1990), antiviral (RIMANDO et al., 1994), anti-PAF (SHEN et al., 1985; BRAQUET; GODFROID, 1986), antidepressiva (DEYAMA; NISHIBE; NAKAZAWA, 2001), antiinflamatória (KASSUYA et al., 2006) e cardiovascular (FARNSWORTH et al., 1985). Demonstrando para as dibenzilbutirolactonas a ação antiviral (CHARLTON, 1998; PICCINELLI et al., 2005), tripanocida (DE SOUZA et al., 2005), antiinflamatória (DE SOUZA et al., 2004), analgésica (DA SILVA et al., 2005) e anticancerígena (LI et al, 2006).

Lopes et al. (1998) demonstraram que a atividade tripanocida de algumas lignanas tetraidrofurânicas sobre as formas tripomastigotas sangüíneas, sem apresentar danos às hemácias foi maior que da violeta de genciana.

Bastos, Albuquerque e Silva (1999) avaliando um grupo de lignanas dibenzilbutirolactônicas biologicamente ativas, isoladas das folhas de Zanthoxyllum naranjillo (Rutacea), vulgarmente chamada de "mamica de cadela", demonstraram a atividade tripanocida da cubebina (17) e do metilpluviatolido (1).

Posteriormente a elevada atividade antiinflamatória da cubebina foi demonstrada (BASTOS et al., 2001) e estudos pré-clínicos de possíveis reações adversas desta substancia 
demonstraram que esta não apresenta qualquer efeito tóxico quando administrada via oral o que torna importante à avaliação deste composto assim como de seus derivados para fins terapêuticos (RODRIGUES, 2002).

Atualmente, a cubebina passou a ser isolada das folhas de Piper cubeba L. (Figura 8) e alguns derivados desta substância foram sintetizados, visando potencializar as atividades biológicas.

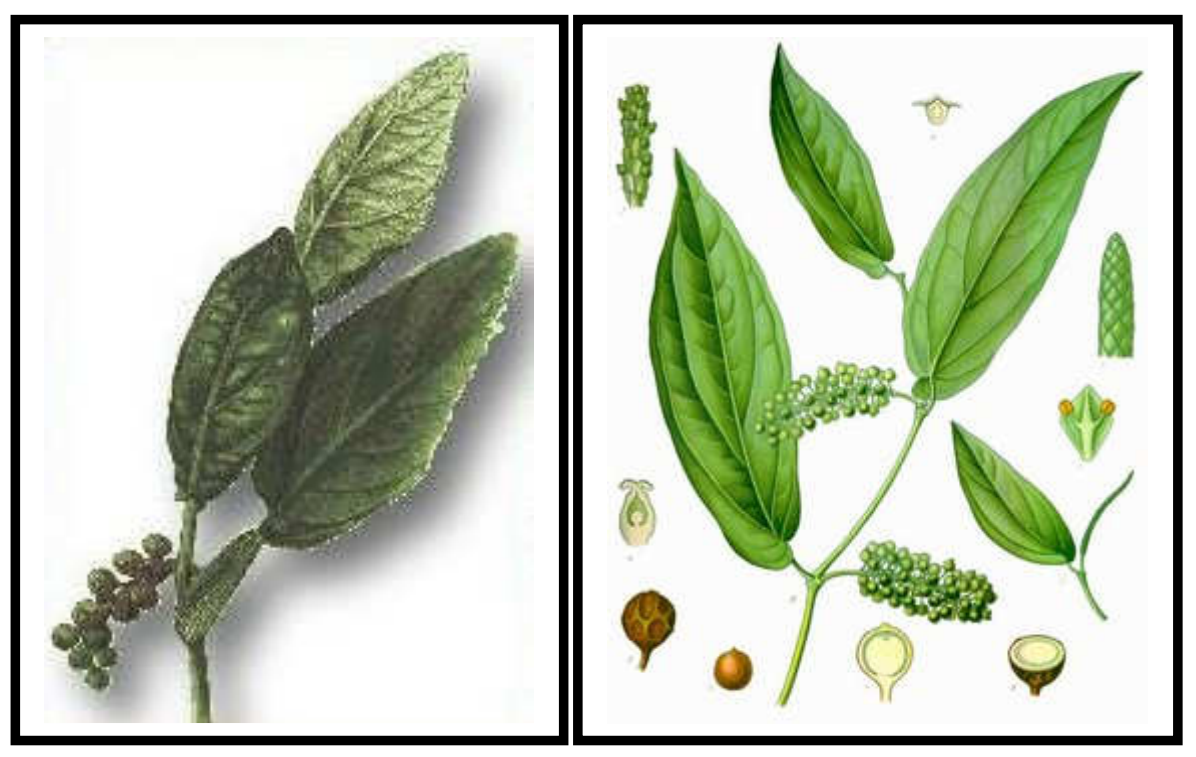

Figura 7. Representação esquemática de Piper cubeba L.

Souza et al. (2004) alterando a estrutura da cubebina, sem modificar no esqueleto básico, demonstraram aumento nos efeitos analgésicos desta pela aminação e acetilação do composto. Ainda, a atividade antiinflamatória e analgésica da hinoquinina (11), 6, 6dinitroinoquinina (15) e da 6, 6 diaminoinoquinina (14), derivados da cubebina foi demonstrada (DA SILVA et al., 2005).

As características estruturais do metilpluviatolido (1), do matairesinol (7) e da hinoquinina (11) foram demonstradas (HELENO et al., 2006) e rota sintética de alguns derivados da cubebina bem como a alta atividade destas substancias sobre formas amastigotas livres da cepa Y de T. cruzi descrita (DE SOUZA et al., 2005). 
Esses estudos evidenciaram, portanto, a necessidade de se investigar os mecanismos da atividade biológica tripanocida destes compostos, assim como de seus derivados, a fim de ampliar suas perspectivas de aplicação.

\subsection{Potencias alvos da atividade tripanocida de fármacos}

Muitos processos bioquímicos vêm despertando o interesse de pesquisadores como alvos terapêuticos para doença de chagas.

Na maioria dos organismos a transição de anaerobiose para aerobiose é acompanhada por um rápido decréscimo nos níveis de utilização da glicose. Esta inibição da glicolise pelo oxigênio é chamada de efeito Pasteur. Em tripanosomatídeos o consumo de glicose ocorre não só em anaerobiose, mas também em condições aeróbicas ("fermentação aeróbica") acompanhadas por um mecanismo inverso ao efeito Pasteur. Este catabolismo peculiar é mediado por enzimas glicolíticas, as quais a maioria é encontrada em uma organela chamada glicosoma (CAZZULO, 1992).

Na circulação sangüínea do hospedeiro, $T$. cruzi necessita da via glicolítica para produção de ATP (BRINGAUD; RIVIERE; COUSTOU, 2006). Durante o processo de degradação da glicose (Figura 8) a enzima glicossomal gliceraldeído-3-fosfato desidrogenase (GAPDH) catalisa a fosforilação oxidativa de gliceraldeído-3-fosfato (GAP) a 1,3bifosfoglicerato (BPG) e sua estrutura tridimensional, determinada por Souza et al. (1998), apresenta significantes diferenças estruturais quando comparada à homóloga humana, o que justifica o interesse por esta via metabólica. 


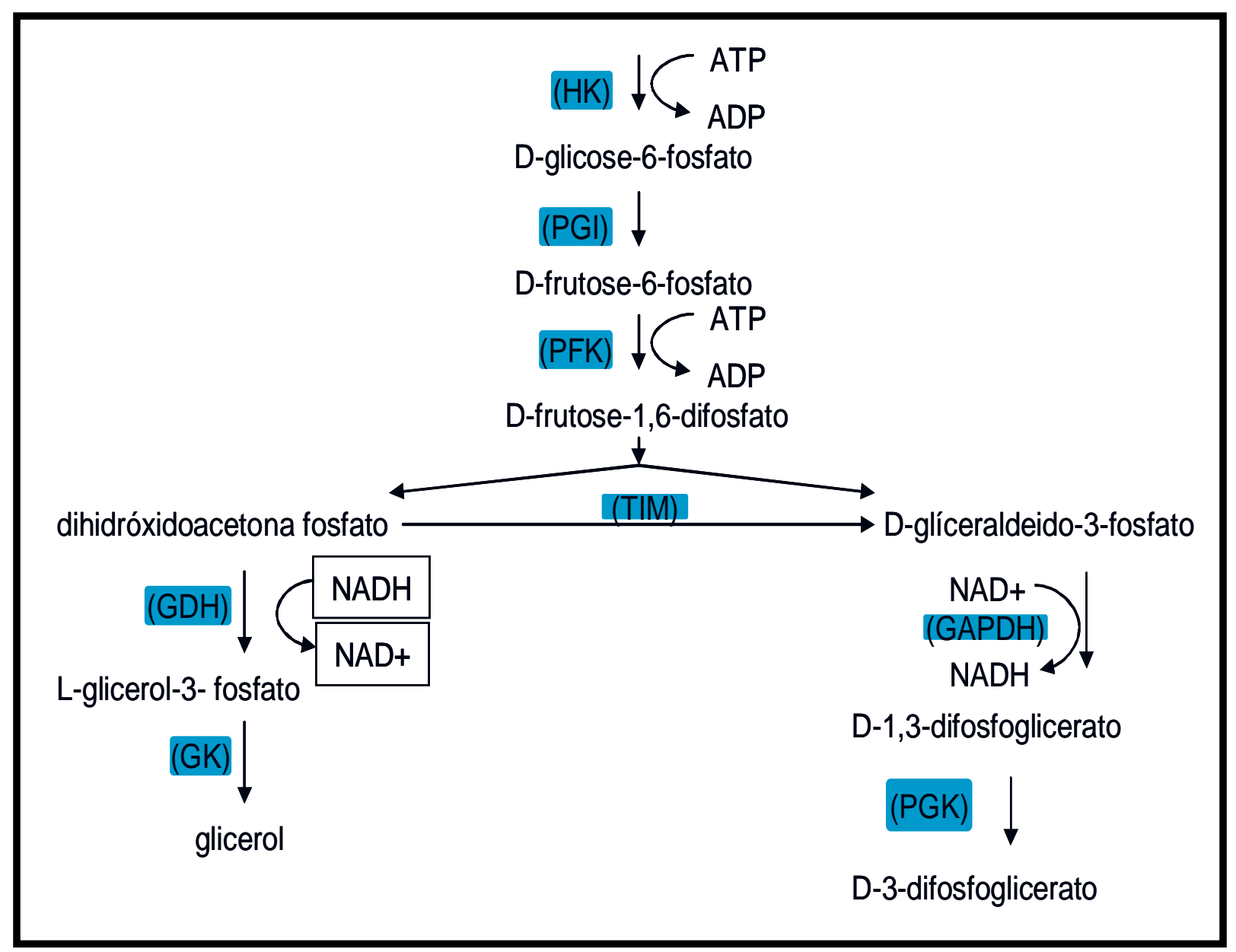

Figura 8. Processo de degradação da glicose pela via glicolítica. Hexoquinase (HK) Fosfoglucose isomerase (PGI) 6-Fosfofrutoquinase (PFK) 6-Fosfofrutoquinase (PFK) Triose fosfato isomerase (TIM) Gliceraldeído 3-fosfato desidrogenase (GAPDH) 3-fosfoglicerato quinase (PGK) Glicerol 3-fosfato desidrogenase (GDH) Glicerol quinase (GK).

Durante a transformação das formas extracelulares "amastigotas-like" em epimastigotas ocorre um decréscimo no nível de algumas enzimas glicolíticas, assim como um aumento no nível de algumas enzimas do ciclo de Krebs e de alguns citocromos (CAZZULO et al., 1985). As formas epimastigotas de $T$ cruzi são dependentes da respiração para proliferação e tem o metabolismo de glicose reduzido durante a hipóxia (STOPPANI et al., 1980). 
Ainda um decréscimo de enzimas glicolíticas e um aumento de enzimas do ciclo de Krebs ocorrem durante a transformação das formas epimastigotas em tripomastigotas metacíclicas (infectantes ao hospedeiro), as quais parecem apresentar um metabolismo essencialmente oxidativo (ADROHER; OSUNA; LUPIANEZ, 1988)

A cadeia respiratória de $T$. cruzi também tem sido explorada como alvo de novos fármacos (MAYA et al., 2006) e alguns compostos como o antioxidante t-butil-4hidroxianisol (BHA) e os derivados da pirimidina tem demonstrado marcantemente efeito inibitório sobre a respiração do parasita (MAYA et al., 2001).

Ainda, de maneira geral, é de se esperar que substâncias com atividade tripanocida atuem, ao menos em parte, pela indução do stress oxidativo sobre o parasita. Apesar de possuir defesas antioxidantes, enzimáticas e não enzimáticas, em relação aos mamíferos, o parasita tem mostrado ser deficiente nos mecanismos antioxidantes, sendo desta forma muito sensível à ação dos radicais livres (TURRENS et al., 2004).

Como outros organismos que vivem em condições aeróbicas, os tripanosomatídeos são expostos a reativos intermediários de oxigênio, tais como anion superoxido $\left(\mathrm{O}_{2}^{-{ }^{-}}\right)$, peróxido de hidrogênio $\left(\mathrm{H}_{2} \mathrm{O}_{2}\right)$ e radical hidroxil $\left(\mathrm{OH}^{\circ}\right)$. Estes componentes são gerados internamente por cofatores e pelo metabolismo de fármacos e externamente pelo sistema de defesa do hospedeiro (DOCAMPO; MORENO, 1986; HALL; JOINER, 1991)

Desta forma, quando o $\mathrm{O}_{2}$ sofre redução incompleta gera anion superóxido e como mecanismos antioxidante, a primeira linha de defesa envolve a remoção de anion superóxido pela enzima superoxido dismutase (SOD), a qual catalisa a transformação do radical superóxido em oxigênio molecular e peróxido de hidrogênio $\left(\mathrm{H}_{2} \mathrm{O}_{2}\right)$, através de alternadas redução e oxidação do metal do sítio ativo (LUDWIG et al., 1991): 


$$
\begin{aligned}
& \text { (1) } \mathrm{Fe}^{3+}+\mathrm{O}_{2}^{-\bullet} \longrightarrow \mathrm{Fe}^{2+}+\mathrm{O}_{2} \\
& \text { (2) } \mathrm{Fe}^{2+}+\mathrm{O}_{2}^{-\bullet}+2 \mathrm{H}^{+} \longrightarrow \mathrm{Fe}^{2+}+\mathrm{H}_{2} \mathrm{O}_{2}
\end{aligned}
$$

Figura 9. Reações catalisadas pela enzima ferro superóxido dismutase (Fe-SOD) de T. cruzi para remoção de superoxido $\left(\mathrm{O}_{2}^{-\bullet}\right)$ e produção de peróxido de hidrogênio $\left(\mathrm{H}_{2} \mathrm{O}_{2}\right)$ e oxigênio molecular $\left(\mathrm{O}_{2}\right)$

As enzimas SOD são classificadas de acordo com o metal presente no seu sítio ativo. O protozoário $T$. cruzi possui enzima superóxido dismutase (SOD) contendo ferro em seu sítio ativo (FeSOD) (LE TRANT et al., 1983), ausente em células de eucariotos, o que explica o interesse sobre fármacos que atuem sobre esta enzima no parasita.

O peróxido de hidrogênio formado é removido, em células de mamíferos, por ação da catalase e de várias peroxidases. No entanto, os tripanosomatideos não contem ou contem pouca catalase e glutationa peroxidase (LEID; SUQUET; TANIGOSHI 1989; DOCAMPO; MORENO, 1990; FLOHE et al., 2003).

Evidências indicam que tripanosomatideos podem metabolizar $\mathrm{H}_{2} \mathrm{O}_{2}$ através de um sistema antioxidante análogo ao glutationa, glutationa redutase e glutationa peroxidase de células de mamíferos, porém menos eficiente (Figura 9). Esta relação pode ter uma importância significativa no modo de ação de substâncias que atuam sobre as defesas antioxidantes do parasita (FAIRLAMB; CERANI, 1992). 


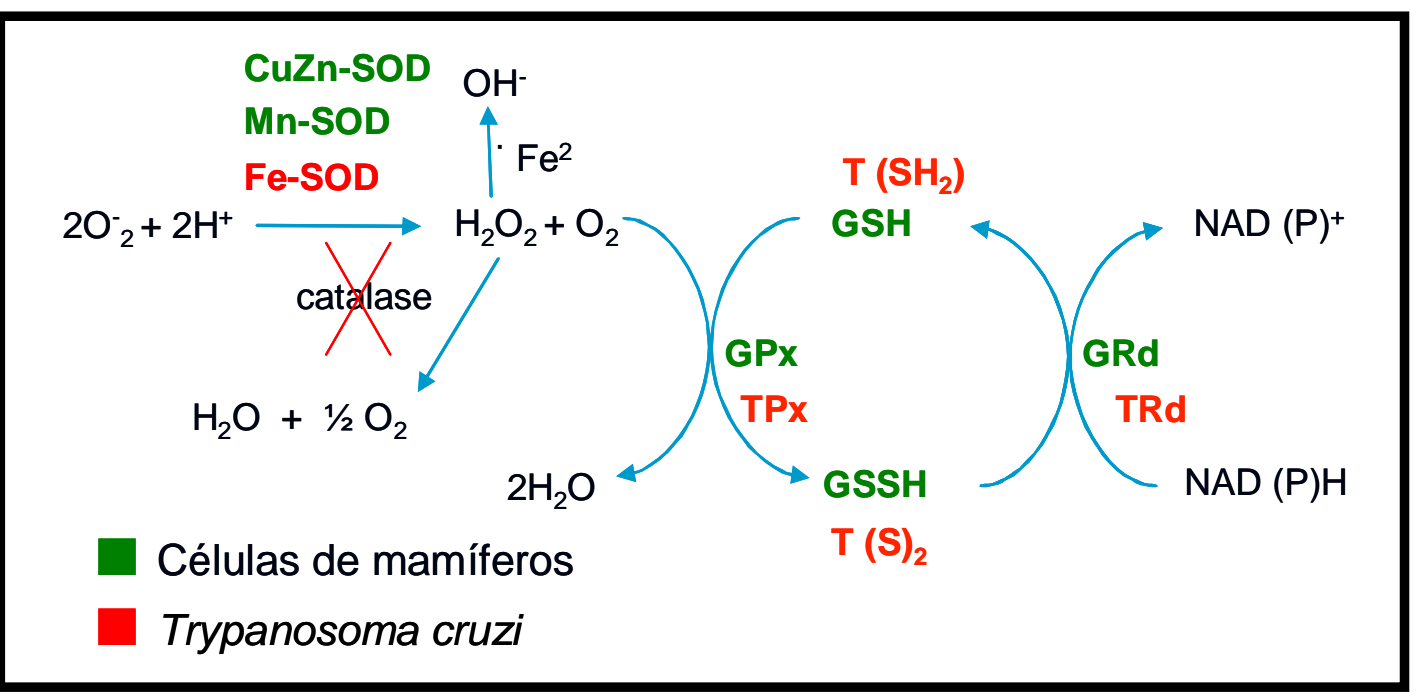

Figura 10. Reações antioxidantes em células de mamífero e em Trypanosoma cruzi. Enzima $\mathrm{Cu}, \mathrm{Zn}$ - superoxido dismutase (CuZn-SOD); Enzima Mn- superoxido dismutase (Mn-SOD); Enzima Fe- superoxido dismutase (Fe-SOD); radical superóxido $\left(\mathrm{O}_{2}{ }^{-}\right)$ peróxido de hidrogênio $\left(\mathrm{H}_{2} \mathrm{O}_{2}\right)$; enzima glutationa peroxidase (GPx); enzima tripanotiona peroxidase (TPx) glutationa oxidada (GSSH); tripanotiona oxidada $\left(\mathrm{T}(\mathrm{S})_{2}\right)$; glutationa redutase $(\mathrm{GRd})$; tripanotiona redutase $(\mathrm{TRd})$; glutationa reduzida $(\mathrm{GSH})$; tripanotiona reduzida $\left(\mathrm{T}(\mathrm{SH})_{2}\right)$.

$\mathrm{O}$ aumento na geração de anion superoxido $\left(\mathrm{O}_{2}^{-\bullet}\right)$ e peróxido de hidrogênio $\left(\mathrm{H}_{2} \mathrm{O}_{2}\right)$ ou a diminuição nas defesas antioxidantes, em presença de $\mathrm{Fe}^{++}$, resulta na produção de radical hidroxil, que por ser altamente reativo causa danos oxidativos nas membranas biológicas, como por exemplo, peroxidação dos lipídeos de membrana (HALLIWELL; GUTTERIDGE, 1992)

A geração de metabólitos tóxicos de oxigênio esta envolvida no modo de ação da violeta de genciana, a qual tem como alvo principal a mitocôndria do parasita (GADELHA et al., 1989). 
Alem disso, Estudos demonstram que o mecanismo envolvido no processo de morte celular programada (apoptose) em cinetoplastidae do genero Trypanosoma é diferente da típica apoptose de mamíferos, sendo um alvo promissor para quimioterapia (DEBRABANT; NAKHASI, 2003).

As modificações morfológicas e bioquímicas associadas com a morte celular programada induzida por soro humano fresco (FHS) nas forma epimastiogotas de T. cruzi incluem a inibição da proliferação do parasita, fragmentação do DNA e ativação de proteases, com manutenção da integridade da membrana plasmática durante o processo (PIACENZA; PELUFFO; RADI, 2001)

A mitocôndria tem um papel central na apoptose, liberando fatores pro-apoptoticos dentro do citosol. Além disso, as espécies reativas de oxigênio (EROS) derivadas da mitocôndria tem sido associadas a fase inicial do processo de apoptose (BELTRAN et al., 2000).

Muitos pesquisadores buscam elucidar os mediadores moleculares e o mecanismo envolvido no processo de morte de tripanosomatídeos. Piacenza et al. (2006) investigando o mecanismo molecular de morte celular programada em $T$. cruzi induzida por FHS demonstraram que este processo em $T$. cruzi dependente do superóxido mitocondrial e que a enzima Fe-SOD exerce papel anti-apoptótico em tripanosomatídeos.

Além disso, um dos mecanismos que controlam a multiplicação do parasita depende diretamente da biossíntese de óxido nítrico (NO) (GAZZINELLI et al., 1992; VESPA; CUNHA; SILVA, 1994). O NO é gerado pela oxidação da arginina em citrulina, e é catalisado pela enzima óxido nítrico sintase (NOS). Três isoformas de NOS já foram descritas: uma, é cálcio-independente - forma induzível ( $\left.\mathrm{NOS}_{2} / \mathrm{iNOS}\right)$, a qual e capaz de gerar altas taxas de NO. As outras, que são cálcio-dependentes são expressas constitutivamente, inclui a NOS neuronal ( $\left.\mathrm{NOS}_{1} / \mathrm{bNOS}\right)$ e NOS endotelial ( $\left.\mathrm{NOS}_{3} / \mathrm{eNOS}\right)$. Em comparação com 
$\mathrm{NOS}_{2}, \mathrm{NOS}_{1}$ e NOS 3 geram taxas relativamente baixas de $\mathrm{NO}$, os quais parecem ter atividade fisiológica significativa (KELLY; BALLIGAND; SMITH, 1996; JAMES, 1995).

O NO produzido por $\mathrm{NOS}_{2}$ durante a fase aguda da infecção experimental por T.cruzi é uma molécula importante na defesa imune (JAMES, 1995) e pode ser ativado por citocinas:

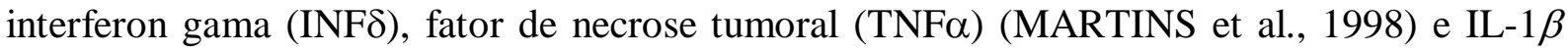
(HUANG et al., 1999). Além disso, o tratamento de camundongos infectados pelo parasita com inibidores de NO sintase, exacerba a infecção (PETRAY, et al., 1994; VESPA; CUNHA; SILVA, 1994).

Apesar do NO ser por si mesmo considerado citotóxico, também reage com o íon superóxido $\left(\mathrm{O}_{2}^{-\bullet}\right)$ para formar peroxinitrito $\left(\mathrm{ONOO}^{-}\right)$, uma molécula ainda mais citotóxica que o seu precursor (RADI et al., 1991; BECKMANN, 1991), que causa oxidação e nitrosilação de lipídeos e tiois, bem como nitrosilação de aminoácidos de proteínas, sendo dessa maneira extremamente tóxica para T.cruzi (DENICOLA et al., 1993). 


\section{Objetivos}

- Avaliar o potencial citotóxico das substâncias

- Avaliar a atividade tripanocida da cubebina (17), do metilpluviatolide (1), do matairesinol (7), da hinoquinina (11), bem como de seus derivados, sobre as formas tripomastigotas e amastigotas de Trypanosoma cruzi

- Avaliar a atividade tripanocida in vivo, em Mus musculus, linhagem Balb/c, das substâncias de maior atividade.

- Analisar o efeito das substâncias sobre algumas rotas metabólicas, avaliando a produção de peróxido de hidrogênio $\left(\mathrm{H}_{2} \mathrm{O}_{2}\right)$ e outros peróxidos, atividade inibitória sobre a enzima gliceraldeído-3-fosfato desidrogenase (GAPDH) de Trypanosoma cruzi, atividade inibitória sobre a enzima ferro superóxido dismutase (Fe-SOD) de Trypanosoma cruzi, o efeito sobre a produção de óxido nítrico e atividade sobre a respiração celular.

Desta forma, este estudo teve como objetivo aprofundar o conhecimento relacionado à atividade tripanocida e citotoxica desta classe de substâncias, abrindo perspectivas para o desenvolvimento de compostos que venham a ser uma nova alternativa no tratamento da doença de Chagas. 
3 MATERIAIS E MÉTODOS 


\section{Materiais e Métodos}

\subsection{Lignanas avaliadas}

Os compostos foram obtidos e sintetizados, pela Prof ${ }^{\mathrm{a}}$. Dr ${ }^{\mathrm{a}}$. Rosângela Silva da Universidade de Franca conforme metodologia descrita por Bastos; Albuquerque e Silva (1999), Udino et al. (1999), Landais; Robin e Lebrun (1991), Souza et al. (2004), Da Silva et al. (2005) e De Souza et al. (2005). A pureza foi estimada por cromatografia líquida de alta eficiência (CLAE) e análise espectral.

\subsection{Manutenção da Cultura de Células}

As células da linhagem LLC-MK 2 (NORVAL, 1979) utilizadas foram cultivadas em meio RPMI 1640 (Sigma) suplementado com 5\% de soro bovino fetal (Cultilab), penicilina G (25 UI/mL), estreptomicina $(25 \mu \mathrm{g} / \mathrm{mL})$ e ciprofloxacina $(10 \mu \mathrm{g} / \mathrm{mL})$. Já as células da linhagem NCTC 929 foram cultivadas em MEM (Sigma) suplementado de 10\% de soro bovino fetal, penicilina $\mathrm{G}(100 \mathrm{U} / \mathrm{ml})$ e estreptomicina $(100 \mu \mathrm{g} / \mathrm{ml})$.

Os cultivos foram mantidos a $37^{\circ} \mathrm{C}$ em atmosfera umedecida contendo $5 \%$ de $\mathrm{CO}_{2}$, sendo o meio renovado a cada dois dias, assim como parte das células removidas uma vez por semana.

\subsection{Avaliação da citotoxicidade in vitro}

A ação citotóxica das substâncias foi avaliada pelo método de MTT, o qual é usado para avaliar in vitro a atividade metabólica ou viabilidade de células de cultura. O método é baseado na redução do MTT [3-(4,5-dimethylthiazol-2-yl)-2,5-diphenyltetrazolium bromide] a formazam (SIEUWERTS et al., 1995).

Em microplacas de 96 poços, células LLC-MK $2\left(5 \times 10^{5}\right.$ células/poço) foram cultivadas em meio RPMI 1640 (Sigma) suplementado com 5\% de soro bovino fetal (Cultilab), 25 
$\mathrm{UI} / \mathrm{mL}$ penicilinae, $25 \mu \mathrm{g} / \mathrm{mL}$ estreptomicina e $10 \mu \mathrm{g} / \mathrm{mL}$ ciporfloxacina. As substâncias foram adicionadas nas concentrações de 0,$5 ; 2 ; 8 ; 32 \mu \mathrm{M}$ e a placa incubada por $24 \mathrm{~h}$ em estufa de $5 \%$ de $\mathrm{CO}_{2}$ a $37^{\circ} \mathrm{C}$.

Após este período as células foram incubadas com MTT $(5 \mathrm{mg} / \mathrm{mL})$ por $4 \mathrm{~h}$, onde então $100 \mu \mathrm{L}$ de isopropanol-ácido foi adicionado. A placa foi mantida a temperatura ambiente até que os cristais formados fossem dissolvidos e a leitura realizada em espectrofotômetro (Tecan) a $570 \mathrm{~nm}$. Os ensaios foram realizados em triplicata. Como controle positivo utilizamos $10 \mu \mathrm{L}$ de Triton X-100 20\% e, como controle negativo solução fisiológica com $10 \%$ de dimetilsulfóxido (DMSO).

A porcentagem de citotoxicidade foi determinada pela a seguinte formula:

$\%$ citotocixidade $=1-[(\mathrm{Y}-\mathrm{N}) /(\mathrm{N}-\mathrm{P})]^{*} 100$

onde: $\mathrm{Y}=$ leitura da densidade óptica dos poços com células e diferentes concentrações das substâncias; $\mathrm{N}=$ leitura da densidade óptica dos poços com células; $\mathrm{P}=$ leitura da densidade óptica dos poços com células e Triton X-100. A dose citotóxica para 50\% das células $\left(\mathrm{CC}_{50}\right)$ foi definida utilizando o método estatístico de curva dose-resposta sigmoidal.

\subsection{Parasitas}

Nos ensaios foram utilizadas, a cepa Y pertencente à Linhagem 1 e constituída por formas tripomastigotas delgadas (PEREIRA DE SILVA; NUSSENZWEIG, 1953), a cepa Bolívia pertencente a linhagem 2 e composta predominantemente por formas tripomastigotas largas (FUNAYAMA; PRADO JUNIOR, 1974) e o clone CL B5, o qual contém o gene da $\beta$ galactosidase que confere alta especificidade e sensibilidade aos ensaios farmacológicos (BUCKNER et al., 1996).

\subsection{Ensaios tripanocidas}




\subsubsection{Sobre as formas tripomastigotas de $T$. cruzi}

Os ensaios foram realizados sobre as formas tripomastigotas das cepas $\mathrm{Y}$ e BOL obtidas do sangue de camundongos swiss, infectados com cada uma das cepas nos respectivos picos de parasitemia, O sangue infectado foi diluído com solução fisiológica $0,9 \%$ e a concentração de parasitas ajustada para aproximadamente $10^{6}$ formas tripomastigotas $/ \mathrm{mL}$. Soluções estoques foram preparadas pela dissolução das substâncias em 100\% de DMSO, de modo a obter uma concentração final de $20 \mathrm{mM}$.

Alíquotas desta solução estoque foram diluídas e adicionadas ao sangue infectado, de forma a se obter concentrações finais de $0,5,8,32$ e $128 \mu \mathrm{M}$, sendo o ensaio realizado em placas de microtitulação (96 poços).

O material foi incubado a $4^{\circ} \mathrm{C}$ por $24 \mathrm{~h}$, sob agitação constante e após este período, a atividade foi verificada quantitativamente (BRENER, 1962). Como controle de atividade, foi utilizada a violeta de genciana $(250 \mu \mathrm{g} / \mathrm{mL}$, controle positivo), bem como o solvente utilizado para a solubilização das substâncias (controle negativo). Os ensaios foram realizados em triplicata.

\subsubsection{Sobre as formas epimastigotas}

Primeiramente formas epimastigotas da cepa CL B5 foram cultivadas a $28^{\circ} \mathrm{C} \mathrm{com}$ meio LIT suplementado com $10 \%$ de soro bovino fetal, penicilina e estreptomicina como descrito por Castellani; Ribeiro e Fernandes (1967).

Os ensaios foram realizados de acordo com a metodologia descrita por Vega et al (2005). As formas epimastigotas $\left(1 \times 10^{5} / \mathrm{mL}\right)$, obtidas do cultivo em fase estacionaria foram cultivadas em placas de 96 poços a $28^{\circ} \mathrm{C}$, por $72 \mathrm{~h}$, as varias concentrações das substâncias $(0,5,8,32,128 \mu \mathrm{M})$. Após este período $50 \mu \mathrm{l}$ da solução de CPRG (chlorophenol red b-Dgalactopyranoside, $400 \mu \mathrm{M}$ em $0.3 \%$ Triton X-100, $\mathrm{pH}$ 7.4) foi adicionado e a placa incubada 
a $37^{\circ} \mathrm{C}$ por $6 \mathrm{~h}$. A absorvância obtida foi lida em $595 \mathrm{~nm}$. Os ensaios foram realizados em triplicata e expressos em porcentagem de atividade $(\% \mathrm{AE})$ de acordo com a seguinte fórmula: $\% \mathrm{AE}=[(\mathrm{AE}-\mathrm{AEB}) /(\mathrm{AC}-\mathrm{ACB})] \times 100$ onde:

$\mathrm{AE}=$ absorvância dos poços tratados;

$\mathrm{AEB}=$ absorvância dos poços contendo meio e substancia;

$\mathrm{AC}=$ absorvância dos poços contendo controle negativo;

$\mathrm{ACB}=$ absorvância dos poços contendo meio de cultura.

Como controles, foram utilizados o benzonidazol e o nifurtimox nas mesmas concentrações das substâncias (controles positivo) e o DMSO, solvente utilizado para a solubilização das substâncias (controle negativo).

\subsubsection{Sobre as formas amastigotas intracelulares}

\subsubsection{Obtenção das formas tripomastigotas infectantes}

Inicialmente, células LLC-MK 2 foram infectadas com aproximadamente $10^{6}$ formas tripomastigotas sangüíneas da cepa Y, obtidas de sangue de camundongos swiss infectados, no pico de parasitemia e células NCTC-929 foram infectadas com epimastigotas da cepa CL B5, obtidas de cultivo com descrito anteriormente. Após um período de aproximadamente 15 dias, grandes quantidades de formas tripomastigotas foram obtidas do sobrenadante dessas culturas, em consequiência da lise das células repletas de parasitas.

O sobrenadante obtido destes cultivos, contendo as formas tripomastigotas juntamente com algumas células, foi submetido à centrifugação $\left(115 \mathrm{~g}\right.$ por $8 \mathrm{~min}$, a $\left.10^{\circ} \mathrm{C}\right)$ onde o sedimento, contendo principalmente células, foi desprezado e o sobrenadante foi novamente centrifugado $\left(1.620 \mathrm{~g}\right.$ por $30 \mathrm{~min}$ a $\left.10^{\circ} \mathrm{C}\right)$. Então, o sedimento foi ressuspendido em meio RPMI 1640 suplementado e as formas tripomastigotas purificadas submetidas à contagem em 
hemocitômetro de Neubauer, para ajustar as quantidades de parasitas utilizadas nos procedimentos experimentais.

\subsubsection{Ensaios sobre a cepa Y de $T$. cruzi}

Os ensaios foram realizados de acordo com Muelas et al. (2002). Em microplacas de 24 poços contendo lamínulas arredondadas, células LLC-MK 2 (5x10 celulas/placa), previamente tratadas com tripsina $(0,25 \%)$ foram cultivadas com meio RPMI suplementado por $48 \mathrm{~h}$, a $37^{\circ} \mathrm{C}$ em ambiente a $5 \%$ de $\mathrm{CO}_{2}$ e umidade de $95 \%$. Formas tripomastigotas obtidas do cultivo foram adicionadas na proporção de 10:1 e incubadas por 24 horas. Após este período, os poços foram lavados com RPMI para retirar os tripomastigotas restantes e as substâncias em análise foram adicionadas nas concentrações de 0,5, 8, 32 e $128 \mu \mathrm{M}$. Quarenta e oito horas depois, o sobrenadante foi retirado e as células contidas nas lamínulas foram fixadas em metanol por 10 minutos e coradas em Giemsa tamponado, $\mathrm{pH}=7,2$. A porcentagem de amastigotas contidas nas células $\left(\mathrm{n}^{\circ}\right.$ A/100células) foi estimada por microscopia. A atividade anti-amastigotas intracelulares (\%AA) foi expressa como:

$\% \mathrm{AA}=\left[1-\left(\mathrm{n}^{\circ} \mathrm{A} / 100\right.\right.$ células tratadas $) /\left(\mathrm{n}^{\circ} \mathrm{A} / 100\right.$ células controles $\left.)\right] \mathrm{x} 100$

Como controle negativo utilizamos a mesma proporção de solvente (DMSO) e como controle positivo, benzonidazol (Roche) nas mesmas concentrações das substâncias avaliadas. Todos os experimentos foram realizados em triplicata.

\subsubsection{Ensaios sobre a cepa CL B5 de T. cruzi}

Os ensaios foram realizados na Universidade Complutense de Madrid, em colaboração com a Prof. Dra. Alicia Gómez-Barrio, conforme descrito por Buckner et al. (1996). Em placas de 24 poços, células NCTC-929 foram cultivadas $\left(2.5 \times 10^{3}\right.$ celulas/poço). Formas tripomastigotas da cepa CL B5, obtidas de cultivo, foram adicionadas na proporção de 1:10 e 
incubadas por $24 \mathrm{~h}$ a $33^{\circ} \mathrm{C}$ com $5 \% \mathrm{CO}_{2}$. Os poços foram então lavados com PBS para remoção das formas tripomastigotas extracelulares e as substâncias em análise foram adicionadas obtendo as concentrações finais de 0,5, 8, 32 e $128 \mu \mathrm{M}$. As placas foram incubadas por 7 dias a $33^{\circ} \mathrm{C}$. Após este período, $10 \mu \mathrm{L}$ of da solução $(400 \mu \mathrm{M}$ em $0.3 \%$ Triton $\mathrm{X}-100, \mathrm{pH} 7.4)$ de Chlorophenol red- $\beta$-D-galactopyranoside (CPRG; Roche, Indianapolis, Ind.) foi adicionada e a placa foi incubada por $4 \mathrm{~h}$ a $37^{\circ} \mathrm{C}$. A reação colorimétrica foi quantificada a $595 \mathrm{~nm}(\mathrm{OD})$ e os resultados expressos em porcentagem de atividade (AA\%), relativa aos poços controles, da seguinte forma:

$\% \mathrm{AA}=100-(\mathrm{OD}$ dos poços tratados $/ \mathrm{OD}$ do controle negativo $) \times 100$

Como controles, foram utilizados o benzonidazol e o nifurtimox nas mesmas concentrações das substâncias avaliadas (controles positivo) e o DMSO, solvente utilizado para a solubilização das substâncias na mesma proporção (controle negativo). Os ensaios foram realizados em triplicata e os respectivos controles de fármaco (meio com as substâncias nas mesmas concentrações) foram subtraídos de todos os resultados.

\subsubsection{Ensaio biológico in vivo}

Em vista dos resultados obtidos nos ensaios in vitro, o dimetoximorelensin racêmico (8), a hinoquinina (11) e a cubebina foram avaliadas in vivo. Para realização dos ensaios in vivo, foram utilizados dois grupos de 120 camundongos albinos, machos, linhagem BALB/C, pesando aproximadamente $20 \mathrm{~g}$ cada, sendo cada grupo dividido em cinco subgrupos, para cada cepa (Y e Bolívia), onde foi efetuado a análise da atividade de cada substância, como segue:

grupo I - controle negativo sem infecção - 5 animais sem infecção;

grupo II- controle negativo infectado- 5 animais inoculados com $4 \times 10^{4}$ parasitas, onde foi avaliado o comportamento parasitêmico das cepas, frente aos animais utilizados; 
grupo III - controle negativo do solvente - 5 animais inoculados com $4 \times 10^{4}$ parasitas e tratados apenas com o solvente utilizado na dissolução das substâncias, onde foi avaliada a possibilidade de atividade do solvente;

grupo IV - controle positivo - 5 animais inoculados com $4 \times 10^{4}$ parasitas, que foram tratados com benzonidazol na dosagem correspondente a $8 \mathrm{mg} / \mathrm{kg}$ de peso corpóreo;

grupo V - grupo tratado - após $48 \mathrm{~h}$ da inoculação intraperitoneal dos parasitas $\left(4 \times 10^{4}\right.$ parasitas), 15 animais foram submetidos a tratamento diário na dosagem correspondente a $8 \mathrm{mg} / \mathrm{kg}$ de peso corpóreo, por via intraperitoneal, durante 10 dias para os animais infectados pela cepa Y, enquanto que para a cepa Bolívia o tratamento teve início após $120 \mathrm{~h}$ da inoculação e durou 20 dias. Foram avaliados o tempo de sobrevida e parasitemia dos animais tratados.

As curvas parasitêmicas foram realizadas por meio da coleta de $5 \mu \mathrm{L}$ de sangue da cauda de cada animal em experimentação, a cada 48 horas para a cepa Y e 72 horas para a cepa Bolívia, sendo o número de parasitas quantificados de acordo com a técnica descrita por Brener (1962).

\subsection{Atividade inibitória sobre a enzima gliceraldeído-3-fosfato desidrogenase (GAPDH) de Trypanosoma cruzi}

A enzima e o substrato (gliceraldeido-3-fosfato G3P) foram fornecidos pelo laboratório de cristalografia de Proteínas e Biologia Estrutural do Instituto de Física de São Carlos-USP para realização dos ensaios, no laboratório de Química Farmacêutica da Faculdade de Ciências Farmacêuticas de Ribeirão Preto-USP. A enzima Gliceraldeido-3fosfato desidrogenase de T. cruzi (TcGAPDH) usada é uma enzima recombinante, obtida em um sistema de expressão de Escherichia coli, preparada e purificada de acordo com os procedimentos estabelecidos por Souza e colaboradores (SOUZA et al., 1998). A 
concentração da enzima utilizada nos ensaios $(0,3 \mathrm{mg} / \mathrm{mL})$ foi determinada pelo método de Bradford (BRADFORD, 1976).

A atividade da enzima foi determinada pela medida espectrofotométrica de $\mathrm{NADH}$ formado em 30 segundos, a 340nm. Utilizando solução de reação (volume final de $1 \mathrm{~mL}$ ) contendo: $50 \mathrm{mM}$ de tampão Tris- $\mathrm{HCl}$ ph 8,6 com $1 \mathrm{mM}$ de EDTA e $1 \mathrm{mM}$ de $\beta$ mecaptoetanol, $30 \mathrm{mM}$ de arseniato de sódio, 2,5 $\mathrm{mM}$ de $\mathrm{NAD}+, 0,3 \mathrm{mM}$ de G3P e $5 \mu \mathrm{g}$ de proteína, sendo que o substrato $(\mathrm{G} 3 \mathrm{P})$ foi adicionado por ultimo, quando iniciou-se imediatamente a leitura da reação (VIEIRA et al., 2001).

A fim de avaliar a porcentagem de inibição da enzima, foram preparadas soluções das amostras na concentração de $2 \mathrm{mM}$ em DMSO, onde alíquotas destas amostras foram adicionadas à reação, de forma a se obter a concentração final de $100 \mu \mathrm{M}$. A concentração final de DMSO utilizada foi de 5\%, concentração essa que não interfere com a atividade da enzima. O controle foi realizado com DMSO no início e no final do experimento para determinar a atividade especifica da enzima. Os ensaios foram realizados em triplicata e a média das medidas espectrofotométricas obtidas ( $\mathrm{L}$ amostra) foram utilizadas para calcular a porcentagem de inibição da enzima GAPDH por meio da seguinte fórmula:

$\%$ inibição $=100-(\mathrm{L}$ amostra $* 100 / \mathrm{L}$ controle $)$

onde: $\mathrm{L}$ amostra= média das medidas espectrofotométricas obtidas para cada amostra; L controle $=$ média das medidas espectrofotométricas obtidas para o controle inicial e final.

\subsection{Produção de $\mathrm{H}_{2} \mathrm{O}_{2}$ e outros peróxidos}

A produção de peróxido de hidrogênio $\left(\mathrm{H}_{2} \mathrm{O}_{2}\right)$ e de outros peróxidos tais como peróxidos lipídicos foi monitorada eletrofluoreticamente com 2'7'-diclorodiidrofluoresceína ( $\mathrm{H}_{2}$ DCFDA), o qual é oxidado ao composto fluorescente diclorofluoresceína (DCF) (CARTHCART; SCHWIERS; AMES 1983). 
Para estes experimentos, formas tripomastigotas obtidas do sobrenadante de cultura do parasita em células de linhagem LLC-MK 2 foram lavadas e a concentração de parasitas ajustada para $1 \times 10^{6}$ parasitas $/ \mathrm{mL}$, em meio de reação contendo sacarose $125 \mathrm{mM}$, KCL 65 mM, Hepes-KOH 10 mM, pH 7,2. Alíquotas das substâncias foram adicionadas ao meio reacional (volume final $1,0 \mathrm{~mL}$ ) de forma a se obter uma concentração final de $32 \mu \mathrm{M}$. $\mathrm{H}_{2}$ DCFDA foi adicionado na concentração de $5 \mu \mathrm{M}$ e as amostras foram incubadas à temperatura ambiente. Como controle positivo utilizamos o hidroperóxido de t-butil (T$\mathrm{BOOH})$ e, como controle negativo os parasitas pré-incubados com a solução de DMSO a $10 \%$.

Para adequação da metodologia, a unidade relativa de fluorescência dos controles foi acompanhada por 60 minutos. Por meio destas avaliações, determinamos 35 minutos de incubação como tempo ótimo para realização das análises em função de diferença entre os controles.

Desta forma, após 35 minutos de incubação, os parasitas foram removidos por centrifugação $\left(8.000 \mathrm{~g}, 4^{\circ} \mathrm{C}, 10 \mathrm{~min}\right)$ e $\mathrm{o}$ sobrenadante imediatamente submetido à determinação fluorescente usando a excitação de $485 \mathrm{~nm}$ e emissão de 520 nm, como descrito por Fang e Beattie (2003), para Trypanosoma brucei. Os ensaios foram realizados em triplicata. A solução estoque de $\mathrm{H}_{2}$ DCFDA (2 $\mathrm{mM}$ ) foi preparada em etanol e estocada a menos $20^{\circ} \mathrm{C}$.

\subsection{Atividade inibitória sobre a enzima superóxido dismutase (SOD) de Trypanosoma} cruzi

Os ensaios foram realizados no laboratório de cristalografia de Proteínas e Biologia Estrutural do Instituto de Física de São Carlos-USP em colaboração com Professor Dr. Richard Charles Garratt. A enzima ferro superóxido dismutase (Fe-SOD) de T. cruzi, 
fornecida pelo laboratório, é uma enzima recombinante obtida em um sistema de expressão de Escherichia coli, preparada e purificada de acordo com os procedimentos estabelecidos por Navarro (2006).

A concentração da enzima foi determinada pelo método de Bradford (BRADFORD, 1976) e a concentração utilizada nos ensaios de $0,12 \mathrm{mg} / \mathrm{mL}$.

A atividade da enzima foi determinada indiretamente pela capacidade da mesma de inibir a auto-oxidação do pirogalol, intermediada pela geração de radical superóxido. O processo de auto-oxidação na mistura reacional (100 mM de tampão Tris-HCl; $1 \mathrm{mM}$ de EDTA; 0,2 mM de pirogalol $\mathrm{pH}$ 7,2) foi monitorado em espectrofotômetro a $420 \mathrm{~nm}$ por 7min (MARKLUND; MARKLUND, 1974; KABIRI; STEVERDING, 2001).

Alíquotas das substâncias foram adicionadas à reação, de forma a se obter a concentração final de $60 \mu \mathrm{M}$. A concentração final de DMSO utilizada foi de $0,3 \%$, concentração essa que não interfere com a atividade da enzima. O controle foi realizado com DMSO no início e no final do experimento. A fim de avaliar possíveis interferências das substâncias no ensaio, estas isoladamente ou em contato com o pirogalol foram monitoradas utilizando as mesmas concentrações utilizadas nas análises.

\subsubsection{Estudos de docking}

A técnica de docking foi utilizada para propor um modo de ligação entre cada uma das substâncias e a Fe-SOD de T. cruzi. Os cálculos foram realizados com o software GOLD 3.1.1 (VERDONK et al., 2003), o qual utiliza um algoritmo genético para realizar docking flexível (com respeito ao ligante). Os parâmetros utilizados nesse algoritmo foram originalmente otimizados a partir de um conjunto de 305 estruturas de complexos com coordenadas depositadas no Protein Data Bank (PDB). Entre os parâmetros default (pré- 
otimizados), utilizou-se uma população de 100 confôrmeros, 100.000 operações, 95 mutações e 95 crossovers.

Para a análise, átomos de hidrogênio foram adicionados e otimizados na estrutura cristalográfica da enzima. Utilizou-se a estrutura da enzima Fe-SOD de T. cruzi resolvida por Navarro (2006), e gentilmente fornecida pelo Prof. Richard Charles Garratt do laboratório de cristalografia de Proteínas e Biologia Estrutural do IFSC-USP. Os resíduos H164b, W162b, F120a, N67b, K38b e Y35b, correspondentes ao canal que leva o radical superóxido até o sítio ativo (Figura 11), foram considerados no cálculo, estando contidos no interior de uma esfera 10 Å de raio criada a partir do oxigênio da hidroxila do resíduo central Y35b.

Cinco orientações de melhor score foram selecionadas pela função GoldScore para cada composto, e a melhor destas foi considerada para as análises. GoldScore classifica as orientações das moléculas em ordem decrescente de afinidade (escore) com o sítio ligante do receptor. Os figuras foram preparadas utilizando-se o programa PyMOL (DELANO, 2002).

Os cálculos foram realizados sob a supervisão do Prof. Dr. Carlos Henrique Tomich de Paula da Silva no laboratório de Química Farmacêutica da Faculdade de Ciências Farmacêuticas de Ribeirão Preto-USP. As estruturas das substâncias foram modeladas, e uma busca conformacional foi realizada utilizando-se o software Spartan 06 (SPARTAN, 2006), com o método de Monte Carlo e o modelo de mecânica molecular MMFF implementados no software.

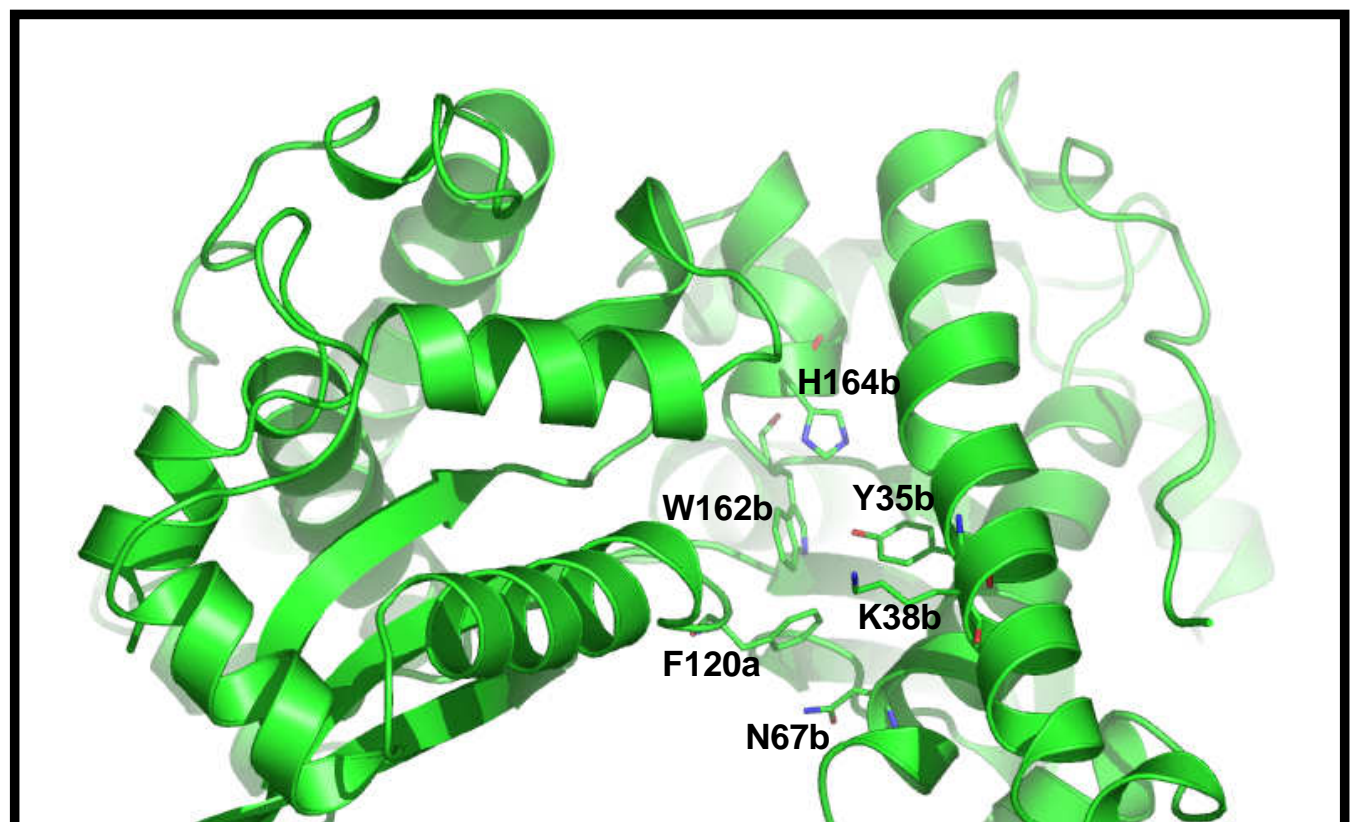


Figura 11. Estrutura tridimensional da enzima ferro superóxido dismutase (Fe-SOD) de $T$. cruzi, indicando os resíduos do canal que leva ao sítio ativo.

\subsection{Ensaio de produção de óxido nítrico}

Camundongos $\mathrm{BALB} / \mathrm{C}$ receberam $1 \mathrm{~mL}$ de tioglicolato $3 \%$, pela via intraperitoneal, 96 horas antes de serem sacrificados e tiveram a cavidade peritoneal lavada com $5 \mathrm{~mL}$ de RPMI puro e estéril (GIORGIO et al., 1998). O lavado foi centrifugado por 10 minutos a 1500rpm e seu sobrenadante desprezado. O sedimento contendo as células foi ressuspenso em $1 \mathrm{~mL}$ de RPMI, contendo $10 \%$ de soro bovino fetal e antibiótico. Desta suspensão, foi retirada alíquota de $10 \mu \mathrm{L}$ que foi diluída em Azul de Tripan, para contagem das células viáveis. Depois de contadas, foram distribuídas aproximadamente $2 \times 10^{5}$ células por poço, em placa de 96 poços e levadas à estufa contendo $5 \%$ de $\mathrm{CO}_{2}$, durante 30 minutos, a $37^{\circ} \mathrm{C}$. Após esse período, o sobrenadante foi desprezado e alíquotas dos compostos diluídas em DMSO, foram adicionadas de forma a se obter as concentrações de 8, 32 e $128 \mu \mathrm{M}$. Após 24 horas, a placa foi centrifugada a $1500 \mathrm{rpm}$ durante 4 minutos e $100 \mu \mathrm{L}$ do sobrenadante foi recolhido e transferido para outra placa de 96 poços. Para revelação da reação, igual volume de reagente de Greiss $(100 \mu \mathrm{L})$ foi adicionado e a leitura realizada em leitor de microplaca, utilizando-se filtro de $540 \mathrm{~nm}$ (GREEN et al., 1982).

\subsection{Atividade inibitória sobre a respiração de $T$. cruzi}


Formas epimastigotas da cepa Y de T. cruzi, provenientes de cultivo axênico, foram centrifugadas a $1700 \mathrm{~g}$ por 20 min e o sedimento ressupendido em tampão contendo $125 \mathrm{mM}$ de sacarose, $65 \mathrm{mM}$ de KCl, $10 \mathrm{mM}$ de HEPES-KOH. A respiração foi avaliada por meio do consumo de oxigênio das mitocôndrias energizadas (1mg de proteína), monitorado polarograficamente em um oxígrafo equipado com eletrodo de Clark (Gilson Medical Eletronics, Middleton, WI, USA), e a velocidade de respiração foi determinada de acordo com Chance e Willians (1956). Ao meio contendo $125 \mathrm{mM}$ de sacarose, $65 \mathrm{mM}$ de KCl, $10 \mathrm{mM}$ de HEPES-KOH, $1 \mathrm{mM}$ de $\mathrm{MgCl}_{2}, 2 \mathrm{mM}$ de $\mathrm{KH}_{2} \mathrm{PO}_{4}$ foram adicionados $500 \mu \mathrm{M}$ de EGTA e substrato para sítio I (glutamato $5 \mathrm{mM}$;, malato $5 \mathrm{mM}$ ) ou para sítio II (succinato $5 \mathrm{mM}$, rotenona $2 \mu \mathrm{M}$ ) (volume final de $1,8 \mathrm{~mL}$ ). A respiração de estado 3 foi iniciada pela adição de ADP (720nmol). Alíquotas das substâncias foram adicionadas de forma a se obter a

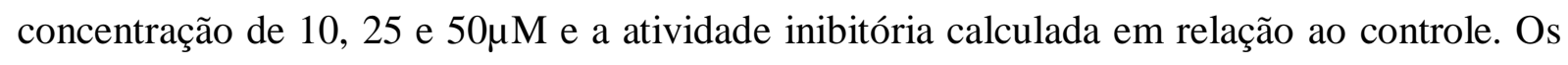
ensaios foram realizados em triplicata.

\subsection{Atividade antioxidante em sistemas livre de células}

\subsubsection{Atividade sequestradora de radical superóxido, utilizando o sistema xantina/xantina oxidase}

A atividade seqüestradora de radical superóxido foi determinada pela razão de redução do nitoblue tetrazolium (NBT) pelos radicais superóxido, utilizando o sistema xantina/xantina oxidase como fonte deste radical. A reação foi monitorada por espectofotometro (Hitaschi U2001) em 560 nm (ROBAK; GRYGLEWSKI, 1988). As amostras foram avaliadas em triplicata.

\subsubsection{Atividade doadora de íons hidrogênio ao radical DPPH}


A redução do 1,1-difenil-2-picril-hidrazil (DPPH) $(64 \mu \mathrm{M})$ pelas substâncias foi avaliada por meio da variação da absorvância da solução em 517 nm, durante 10 e 30 minutos após adição de acetato de sódio $40 \mathrm{mmol} / \mathrm{L}$, ph 5,5 e de etanol (volume final de $1 \mathrm{~mL}$ ) (SUJA; JAYALEKSHMY; ARUMUGHAN, 2004).

\subsection{Ensaios com mitocôndrias isoladas}

\subsubsection{Isolamento das mitocôndrias}

As mitocôndrias foram isoladas por centrifugação (PEDERSEN et al., 1978). Hamster Golden Syrian machos pesando aproximadamente $200 \mathrm{~g}$ foram mortos por deslocamento cervical e em seguida decapitados em guilhotina, o figado foi imediatamente removido, picotado em meio contendo sacarose $250 \mathrm{mmol} / \mathrm{L}$, EGTA 1 mmol/L e HEPES-KOH 10 mmol/L $(\mathrm{pH} 7,4)$ e homogeneizado três vezes por 15 segundos em homogenizador PotterElvehjen. A suspensão foi centrifugada a 770 g por 5 minutos e o sobrenadante centrifugado a $9800 \mathrm{~g}$, por 10 minutos. O sedimento foi ressuspenso com $10 \mathrm{~mL}$ de meio contendo sacarose 250 mmol/L e HEPES-KOH 10 mmol/L (pH 7,2) para utilização.

\subsubsection{Efeitos na produção de $\mathrm{H}_{2} \mathrm{O}_{2}$}

A produção de $\mathrm{H}_{2} \mathrm{O}_{2}$ pelas mitocôndrias (1 $\mathrm{mg}$ de proteína) foi monitorada espectrofluorimetricamente com o corante diacetato de 2',7'-diclorodihidrofluoresceína ( $\mathrm{H}_{2}$ DCFDA), o qual é oxidado ao composto fluorescente DCF, utilizando 503 e $529 \mathrm{~nm}$ para excitação e emissão respectivamente (CARTHCART; SCHWIERS; AMES, 1983).

\subsubsection{Efeitos na respiração mitocondrial}

A respiração foi avaliada por meio do consumo de oxigênio das mitocôndrias energizadas (1 mg de proteína), monitorado polarograficamente em um oxígrafo equipado com eletrodo de Clark (Gilson Medical Eletronics, Middleton, WI, USA), e a velocidade de 
respiração foi determinada de acordo com Chance e Willians (1956). Ao meio contendo 125 $\mathrm{mM}$ de sacarose, $65 \mathrm{mM}$ de $\mathrm{KCl}, 10 \mathrm{mM}$ de HEPES-KOH, $1 \mathrm{mM}$ de $\mathrm{MgCl}_{2}, 2 \mathrm{mM}$ de $\mathrm{KH}_{2} \mathrm{PO}_{4}$ foi adicionado $500 \mu \mathrm{M}$ de EGTA e substrato para sítio I (glutamato $5 \mathrm{mM}$;,malato 5 $\mathrm{mM}$ ) ou para sítio II (succinato $5 \mathrm{mM}$, rotenona $2 \mu \mathrm{M}$ ) (volume final de $1,8 \mathrm{~mL}$ ). A respiração de estado 3 foi iniciada pela adição de ADP (720 nmol). Alíquotas das substâncias foram adicionadas de forma a se obter a concentração de 2,5, 5, 10, 25, 50 e $100 \mu \mathrm{M}$ de acordo com atividade de cada substancia e a atividade inibitória calculada em relação ao controle. Os ensaios foram realizados em triplicata.

\subsubsection{Atividade inibitória sobre NADH desidrogenase}

Para preparação das partículas submitocondriais o sedimento de mitocôndrias foi congelado a $-20^{\circ} \mathrm{C}$ por $24 \mathrm{~h}$. Após este período, o sedimento foi resuspendido a $20 \mathrm{mg}$ de proteína/mL. A suspensão mitocondrial foi submetida a 5 oscilações sônicas de 10 min com 30 segundos de intervalos, usando 80W. A suspensão foi centrifugada a 9750 g por 10 min e as partículas submitocondriais foram isoladas no sobrenadante, por centrifugação deste a $100.000 \mathrm{~g}$ durante $1 \mathrm{~h}$. Estas foram então armazenadas a $-70^{\circ} \mathrm{C}$.

A atividade de NADH desidrogenase foi avalida a $30^{\circ} \mathrm{C}$ por meio da diminuição da absorbância a 340nm utilizando $100 \mu \mathrm{M}$ de NADH como substrato, meio contendo sacarose (125 mM), KCL (65 mM) e Hepes-KOH (10 mM), pH 7,2, EGTA $(0,2 \mathrm{mM})$ e partículas submitocondriais $(10 \mu \mathrm{g}$ de proteína/mL). Alíquotas das substâncias foram adicionadas de forma a se obter a concentração de $\mathrm{IC}_{50}$ de cada substancia obtida nos ensaios de respiração mitocondrial e a atividade inibitória calculada em relação ao controle. Os ensaios foram realizados em triplicata.

\subsubsection{Ensaio virtual de docking}


A técnica de docking foi para propor um modo de ligação entre cada uma das substâncias e subunidade B8 da enzima NADH desidrogenase humana (codigo PDB 1S3A). Os cálculos foram realizados com o software GOLD 3.1.1 (VERDONK et al., 2003), o qual utiliza um algoritmo genético para realizar docking flexível (com respeito ao ligante). Os parâmetros utilizados nesse algoritmo foram originalmente otimizados a partir de um conjunto de 305 estruturas de complexos com coordenadas depositadas no Protein Data Bank (PDB). Entre os parâmetros default (pré-otimizados), utilizou-se uma população de 100 confôrmeros, 100.000 operações, 95 mutações e 95 crossovers.

Como estrutura desta subunidade da enzima utilizada foi resolvida por ressonância magnética nuclear (RMN) as orientações dos átomos de hidrogênio também foram consideradas (BROCKMANN et al., 2004). Os resíduos Y41, I37, R34, Q25, E57, R56, I55, L54, I53, P52 e R20 (Figura 12), correspondentes a um dos sítios de interação da enzima (BROCKMANN et al., 2004) foram considerados no cálculo, estando contidos no interior de uma esfera $15 \AA ̊$ de raio criada a partir do carbono gama do resíduo central I53.

Cinco orientações de melhor score foram selecionadas pela função GoldScore para cada composto, e a melhor destas foi considerada para as análises. GoldScore classifica as orientações das moléculas em ordem decrescente de afinidade (escore) com o sítio ligante do receptor. Os figuras foram preparadas utilizando-se o programa PyMOL (DELANO, 2002).

Os cálculos foram realizados sob a supervisão do Prof. Dr. Carlos Henrique Tomich de Paula da Silva no laboratório de Química Farmacêutica da FCFRP-USP. As estruturas das substâncias foram modeladas, e uma busca conformacional foi realizada utilizando-se o software Spartan 06 (SPARTAN, 2006), com o método de Monte Carlo e o modelo de mecânica molecular MMFF implementados no software. 


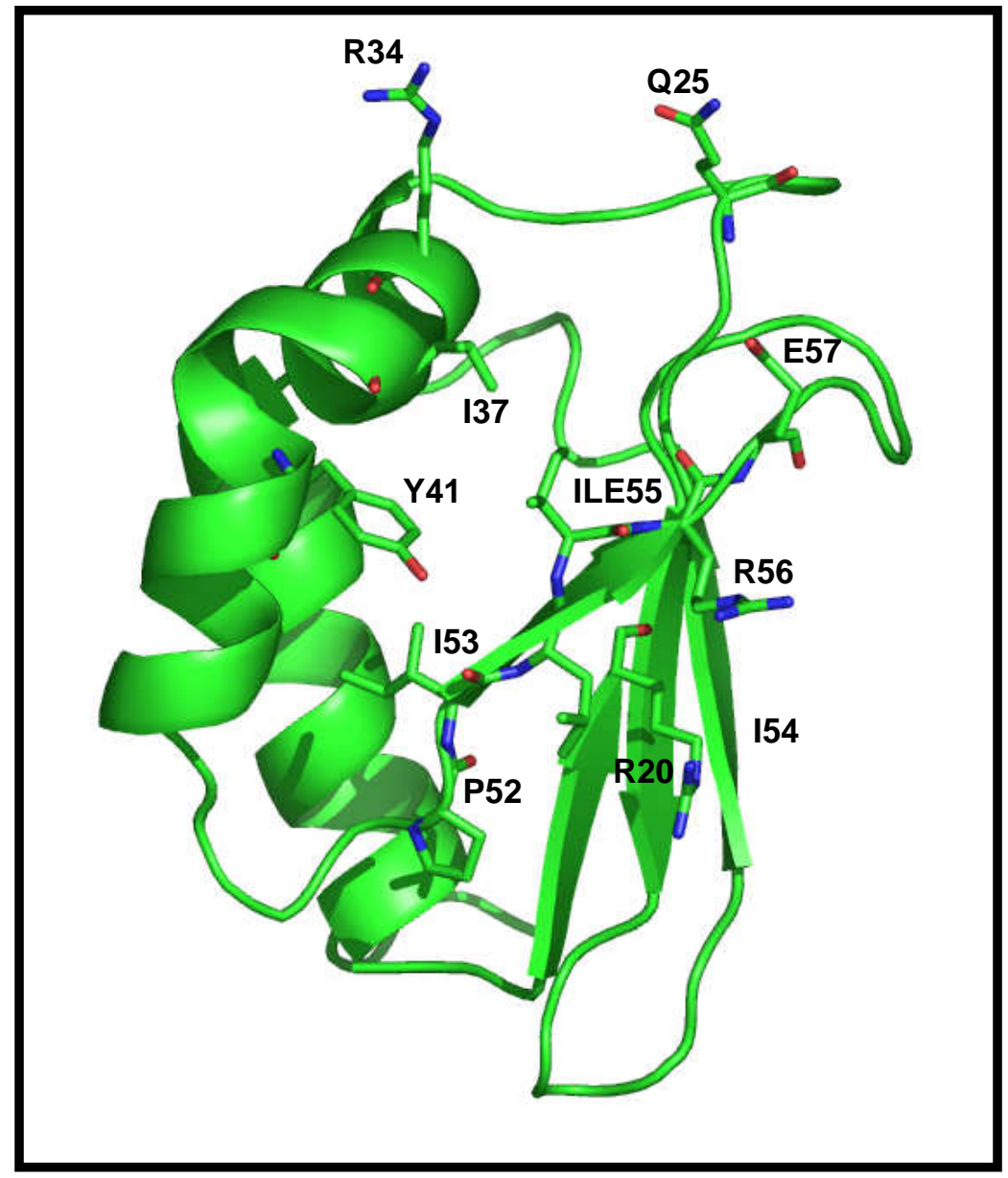

Figura 12. Estrutura tridimensional da subunidade B8 da enzima NADH desidrogenase humana, indicando os resíduos conservados utilizados na analise

3.13 Análise dos danos ultraestruturais de $T$. cruzi por microscopia eletrônica de transmissão (MET). 
Formas epimastigotas de T. cruzi foram cultivadas em tubos descartáveis de $12 \mathrm{~mL}$, durante a fase exponencial da curva de crescimento foram adicionadas aos cultivos alíquotas das soluções de dimetoximorelensin racêmico (8), de forma a se obter uma concentração final de 64, 96 e $128 \mu \mathrm{M}$, concentrações que quando mantidas em contato com o parasita por $72 \mathrm{~h}$ determinaram aproximadamente $100 \%$ de atividade tripanocida. Os cultivos foram mantidos em contato com as substâncias por 24, 48 e 72 h e após este período as amostras foram processadas para MET. Os experimentos foram realizados em triplicata.

\subsubsection{Preparação das amostras}

\subsubsection{Fixação}

Decorridos os respectivos tempos, os cultivos foram centrifugados a $1100 \mathrm{~g}$ por 10 min. O sedimento de epimastigotas foi então submetido a sucessivas lavagens com tampão milloning e fixado com solução de gluteraldeido a $2 \%$ por 70 min a temperatura ambiente. Após este período as amostras foram centrifugadas a $1100 \mathrm{~g}$ por $10 \mathrm{~min}$, submetidas às sucessivas lavagens com tampão de lavagem para retirada da solução fixadora e mantidas em solução de lavagem por $24 \mathrm{~h}$ a $4^{\circ} \mathrm{C}$. As amostras então foram novamente centrifugadas e mantidas em tampão milloning a $4^{\circ} \mathrm{C}$ até que todas as amostras, dos diferentes dias, fossem fixadas.

\subsubsection{Pré-inclusão em ágar bacteriológico a $2 \%$}

Depois de fundido o ágar foi resfriado a $60^{\circ} \mathrm{C}$, temperatura em que não se corre o risco de danificar as amostras. A cada sedimento foram adicionadas duas gotas de ágar e o mesmo foi ressuspendido de forma a obter uma solução homogênea. Depois de solidificadas as amostras foram submergidas em tampão milloning e mantidas a $4^{\circ} \mathrm{C}$. 


\subsubsection{Pos fixação}

Uma pequena porção de amostra do ágar contendo as formas epimastigotas foi obtida com auxilio de uma lâmina cortante e submergida em solução de tetróxido de ósmio a $1 \%$ durante $90 \mathrm{~min}$, a temperatura ambiente e ao abrigo da luz. Após este período as amostras foram lavadas com água destilada para total retirada da solução pos fixadora.

\subsubsection{Desidratação}

A desidratação foi realizada mantendo as amostras por 30 min em soluções crescentes de acetona a 50\%, 70\%, 80\%, 90\%, 100\% e 100\% anidra. Durante a desidratação com acetona a 70\%, para aumentar o contraste, as amostras foram mantidas em acetato de uranilo a $1 \%$ (em acetona $70 \%$ ) a $4^{\circ} \mathrm{C}$ por uma noite. Ao dia seguinte se procederam as demais desidratações.

\subsubsection{Inclusão em resina Spurr}

As amostras foram submergidas, por 60 min a temperatura ambiente, em sucessivas soluções de mescla plástica: acetona anidra, onde foi se aumentando as concentrações de mescla plástica na proporção de 1:3, 2:2, 3:1 à medida em que se foi diminuindo a concentração de acetona. Então foi adicionada a mescla plástica pura as amostras e estas foram mantidas a $4^{\circ} \mathrm{C}$ por uma noite. A resina Spurr pura então foi substituída por uma recém preparada e as amostras foram acondicionadas em cápsulas de polimerização submersas em resina. Para polimerização da resina as cápsulas foram mantidas a $76^{\circ} \mathrm{C}$ por $48 \mathrm{~h}$.

\subsubsection{Microtomia}

Em vista da disponibilidade estas avaliações foram apenas realizadas com algumas amostras processadas. A partir das amostras incluídas em resina foram realizados os cortes semi finos $(0,5-0,7 \mu \mathrm{m})$ para localização das amostras e sucessivamente os cortes finos (60-90 
$\mathrm{nm})$. Estes cortes foram depositados em grades de cobre de $3,05 \mathrm{~mm}$, cobertas com uma fina camada de Formvar a 0,2\% em clorofórmio.

\subsubsection{Coloração}

Primeiro as amostras foram contrastadas com acetato de uranilo a $1 \%$, submergindo cada grade com durante 30 min em uma gota desta solução. Após este período as grades foram lavadas com água destilada e submergidas em uma gota de citrato de chumbo por 4 min. As amostras foram novamente lavadas em água destilada e guardadas para observação ao microscópio.

\subsubsection{Microscopia eletrônica de transmissão}

As amostras referentes a substancia 8 foram examinadas em microscópio eletrônico de transmissão Zeiss EM-10. As placas fotográficas obtidas foram reveladas e passadas a papel para avaliação dos danos ultraestruturais.

\subsection{Análise estatística}

Para análise estatística assim como para diversos cálculos matemáticos dos resultados, utilizamos o software GraphPad prisma 3.0. Foi utilizado o teste One-Way ANOVA, complementado pela análise de Tukey, para determinação dos níveis de significância da atividade das substâncias nos ensaios in vitro. Para a determinação de $\mathrm{IC}_{50}$,e $\mathrm{CC}_{50}$ foi utilizado o método estatístico de curva dose-resposta sigmoidal. 


\section{RESULTADOS E DISCUSSÃO}

\section{Resultados e Discussão}

\subsection{Avaliação da atividade tripanocida in vitro}

Com o intuito de selecionar as substâncias de maior potencial tripanocida e de verificar o efeito das modificações estruturais sobre esta atividade, a atividade tripanocida das substâncias foi avaliada in vitro.

\subsubsection{Sobre as formas epimastigotas e amastigotas intracelulares da cepa CL de $T$. cruzi}

O clone CL B5 utilizado contém o gene da $\beta$-galactosidase que confere alta especificidade e sensibilidade aos ensaios farmacológicos (BUCKNER et al., 1996). Apesar deste clone ser obtido da cepa CL, cepa pertencente ao grupo T. cruzi II, apresenta em relação a esta várias diferenças no comportamento biológico (LE-SENNE et al., 2002) e sua caracterização molecular ainda não foi descrita.

Nas análises realizadas sobre a cepa CL de T. cruzi a atividade tripanocida das substâncias foi primeiramente avaliada sobre as formas epimastigotas desta cepa e apenas aquelas que apresentaram significativa atividade para estas formas foram também avaliadas sobre suas formas amastigotas intracelulares.

Na Tabela 4 podemos verificar que as substâncias 11 e 8 foram as que apresentaram maior atividade tripanocida sobre as formas epimastigotas da cepa CL (IC50=0.67; $3.89 \mu \mathrm{M}$ 
respectivamente), sendo a substância 11 mais ativa que o nifurtimox $(\mathrm{IC50}=3.08 \mu \mathrm{M})$ e que o benzonidazol $($ IC50= $30.89 \mu \mathrm{M})$ e a substância 8 mais ativa que o benzonidazol . Já as demais substâncias apresentaram baixa atividade tripanocida sobre estas formas do parasita.

Tabela 4 - Atividade tripanocida das substâncias 8, 11, 15, 17 e 19 sobre as formas epimastigotas da cepa CL de Trypanosoma cruzi

Substâncias

dimetoximorelensin racêmico (8)

(-) hinoquinina (11)

(-)-6,6 -dinitro-hinoquinina (15)

(-)-cubebina (17)

(-)-9`-O-benzil-cubebina (19)

nifurtimox

benznidazole
$\operatorname{IC50}(\mu \mathrm{M})$

3.89

0.67

374.60

100.90

72.09

3.08

30.89

Controle negativo- LIT com $1 \%$ de DMSO

A substância 15 que da mesma forma que a substância 11 difere da cubebina (17) pela presença do grupamento carbonílico no carbono 9, apresentou baixa atividade tripanocida sobre as formas epimastigotas da cepa CL. No entanto a substância 11 apresenta alta atividade tripanocida sobre estas formas e a comparação à substância 15 indica que a atividade biológica tripanocida sobre estas formas foi significativamente afetada pela presença do grupo nitro na posição 6 e 6 dos anéis aromáticos presentes no composto 15. 
Em vista destes resultados as substâncias 8 e 11 também foram avaliadas sobre as formas amastigotas intracelulares desta cepa (Tabela 5) sendo as duas substâncias menos ativas para as formas amastigotas que para as formas epimastigotas, do mesmo modo como mostrado por outros autores (MUELAS et al., 2002).

Tabela 5 - Atividade tripanocida das substâncias 8 e 11 sobre as formas amastigotas da cepa CL de Trypanosoma cruzi

\begin{tabular}{lc}
\hline \multicolumn{1}{c}{ Substâncias } & IC50 $(\boldsymbol{\mu M})$ \\
\hline dimetoximorelensin racêmico (8) & 68.41 \\
(-) hinoquinina (11) & 18.36 \\
nifurtimox & 3.54 \\
benzonidazol & 20.00 \\
\hline
\end{tabular}

Controle negativo- RPMI com $1 \%$ de DMSO

Nessas circunstâncias, a substância 11 também foi a que apresentou maior atividade tripanocida sobre as formas amastigotas da cepa $\mathrm{CL}$, com valores de $\mathrm{IC}_{50}$ similares ao do benzonidazol $\left(\mathrm{IC}_{50}=20 \mu \mathrm{M}\right)$, porém menores que ao do nifurtimox que é um composto extremamente ativo, mas proibido no Brasil por provocar varias reações adversas (CROFT, 1997).

De maneira geral a substância 8 além de apresentar atividade sobre as formas tripomastigotas da cepa Y e Bolívia, também demonstrou alta atividade tripanocida sobre as formas epimastigotas da cepa $\mathrm{CL}\left(\mathrm{IC}_{50}=3,89 \mu \mathrm{M}\right)$ e moderada atividade sobre as formas 
amastigotas desta cepa $\left(\mathrm{IC}_{50}=68,41 \mu \mathrm{M}\right)$ e a substância 11 apresentou significativa atividade tripanocida em todas as avaliações realizadas.

\subsection{Potenciais mecanismos da ação tripanocida avaliados}

\subsubsection{Atividade inibitória sobre a enzima gliceraldeído-3-fosfato desidrogenase}

\section{(GAPDH) de Trypanosoma cruzi}

Em vistas dos resultados representados na Tabela 6, podemos verificar que a atividade tripanocida das substâncias não se dá pela inibição da enzima GAPDH de $T$. cruzi e que as alterações estruturais realizadas não modificaram significativamente a ação em relação à inibição da enzima.

Tabela 6 - Atividade específica e porcentagem de inibição da enzima gliceraldeído-3-fosfato desidrogenase (GAPDH) de Trypanosoma cruzi

\begin{tabular}{ccc}
\hline Substância (100 $\boldsymbol{\mu M})$ & Atividade específica da amostra & \% de inibição da GAPDH \\
\hline 1 & 80,85 & $0 \%$ \\
2 & 79,40 & $0 \%$ \\
3 & 76,40 & $0 \%$ \\
4 & 76,37 & $0 \%$ \\
5 & 73,35 & $0 \%$ \\
6 & 73,23 & $0 \%$ \\
7 & 74,29 & $0 \%$ \\
8 & 74,21 & $0 \%$
\end{tabular}




\begin{tabular}{ccc}
9 & 67,84 & $4,5 \%$ \\
10 & 66,57 & $6,29 \%$ \\
11 & 82,94 & $0 \%$ \\
12 & 78,03 & $0 \%$ \\
13 & 79,64 & $0 \%$ \\
14 & 79,96 & $0 \%$ \\
15 & 67,98 & $0 \%$ \\
16 & 68,62 & $0 \%$ \\
17 & 74,72 & $0 \%$ \\
18 & 69,52 & $0 \%$ \\
19 & 65,02 & $2,78 \%$ \\
20 & 65,82 & $1,58 \%$ \\
\hline
\end{tabular}

\subsubsection{Produção de $\mathrm{H}_{2} \mathrm{O}_{2}$ e de outros peróxidos}

Os resultados apresentados na Figura 15 demonstram que as formas tripomastigotas, tanto da cepa Y quanto da Bolívia na presença das substâncias, não aumentaram a produção de peróxidos, demonstrando uma tendência a diminuírem a produção basal destes.

cepa Y

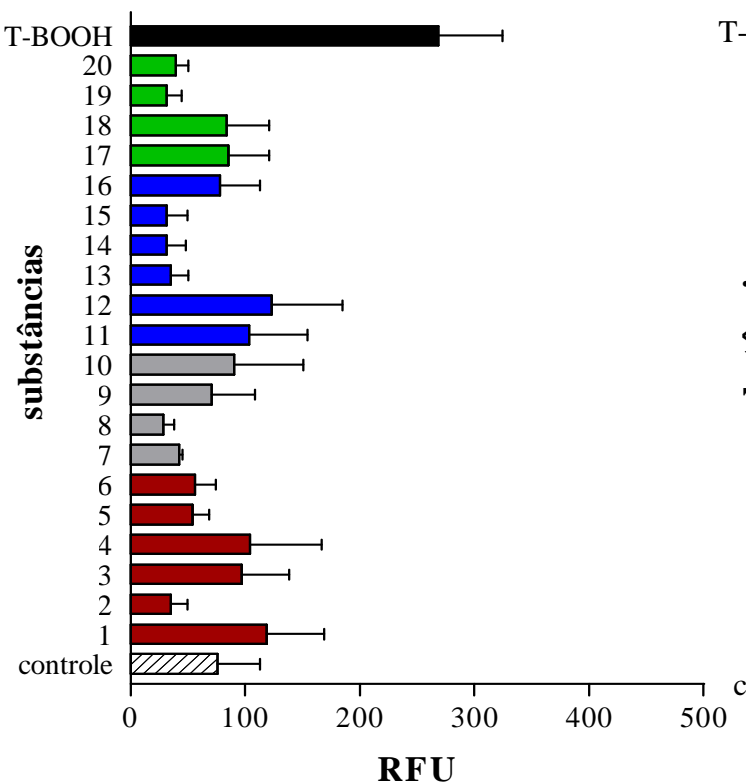

\section{cepa Bolívia}

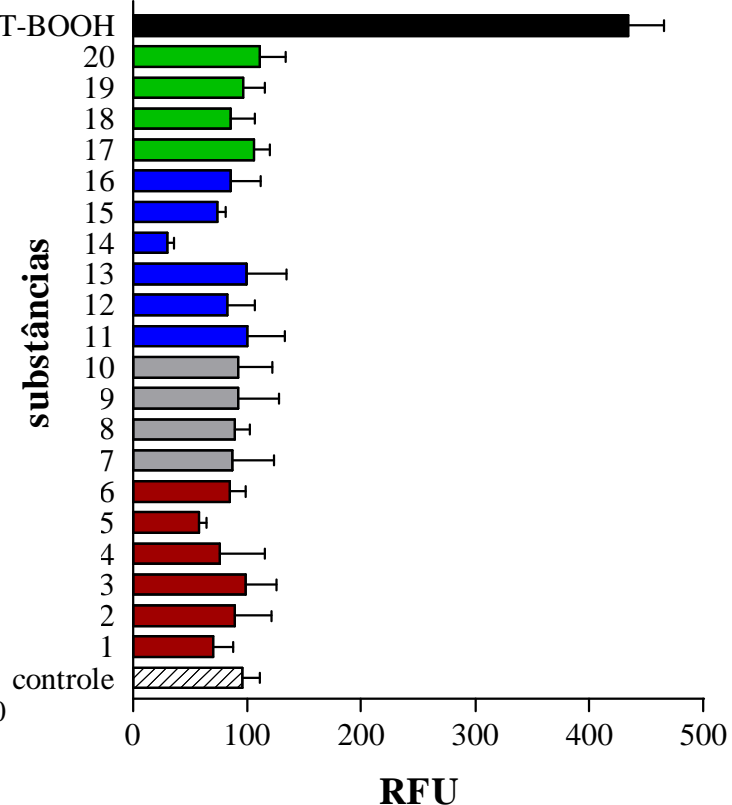


Figura 15. Avaliação das modificações induzidas pelas substâncias na produção de peróxido de hidrogênio e de outros peróxidos pelas formas tripomastigotas da cepa $\mathrm{Y}$ e Bolívia de Trypanosoma cruzi. T-BOOH: hidroperóxido de t-butil (controle positivo); RFU: Unidade Relativa de Fluorescência

Alguns fármacos como o nifurtimox e a violeta de genciana atuam sobre o parasita por induzir o aumento da geração de radicais livres (DOCAMPO; MORENO, 1990; RAETHER; HANEL, 2003). Por ser deficiente nos mecanismos antioxidantes, comparado às células do hospedeiro, $T$. cruzi tem se mostrado mais sensível a ação dos radicais livres, particularmente ao peróxido de hidrogênio por não apresentar catalase, enzima antioxidante responsável pela conversão do peróxido de hidrogênio em água e oxigênio molecular (TURRENS; MCCORD, 2006). Contudo, de acordo com nossos resultados podemos verificar que a ação tripanocida dessa classe de substâncias provavelmente não ocorre por meio do aumento na produção de peróxidos.

Embora não significativo, o decréscimo da produção basal de peróxidos, observado principalmente nas substâncias 14 e 15, pode sugerir um potencial antioxidante a essa classe de substâncias. Contudo, conforme demonstrado posteriormente, esta atividade foi avaliada e os resultados indicaram que apesar de realmente inibirem a produção de peróxidos também em mitocôndrias as substâncias não apresentaram atividade sequestradora de radicais livres.

\subsection{Atividade anti-oxidante em sistemas livre de células}

\subsubsection{Atividade seqüestradora de radical superóxido, utilizando o sistema xantina/xantina oxidase.}


A enzima xantina oxidase catalisa a oxidação da xantina em ácido úrico. Durante a reoxidação da xantina oxidase o oxigênio molecular atua como aceptor de elétrons, produzindo o radical superóxido que reduz o NBT presente no meio reacional, causando um aumento na absorbância a $560 \mathrm{~nm}$ e a atividade seqüestradora de radical superóxido é calculada pela diminuição do aumento de NBT reduzido.

De uma maneira geral, as substâncias avaliadas também apresentaram baixa capacidade de seqüestrar radical superóxido (Figura 23).

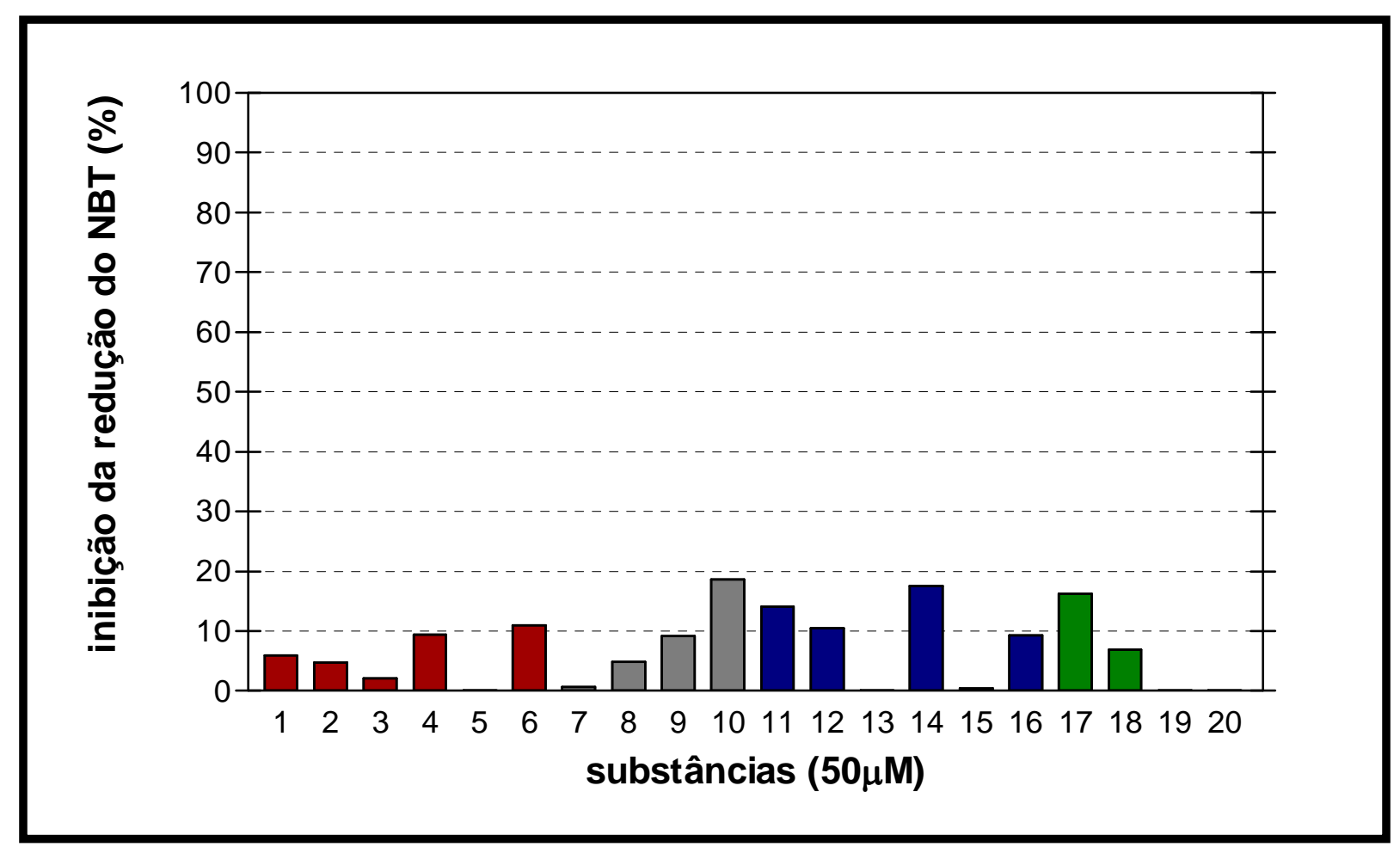

Figura 23. Representação gráfica da avaliação da atividade seqüestradora de radical superóxido pelas substâncias

\subsubsection{Atividade doadora de íons hidrogênio ao radical DPPH}

O DPPH é um radical livre instável que aceita um elétron de hidrogênio convertendose numa molécula estável. Quando instável possui uma forte absorção a $517 \mathrm{~nm}$ e assim que 
se torna estável esta absorção diminui. A mudança produzida é utilizada para determinar a habilidade de várias moléculas em doar íons hidrogênio aos radicais livres (DINIS et al., 1994). Todas as substâncias avaliadas apresentaram baixa capacidade doadora de íons hidrogênio (Figura 24).

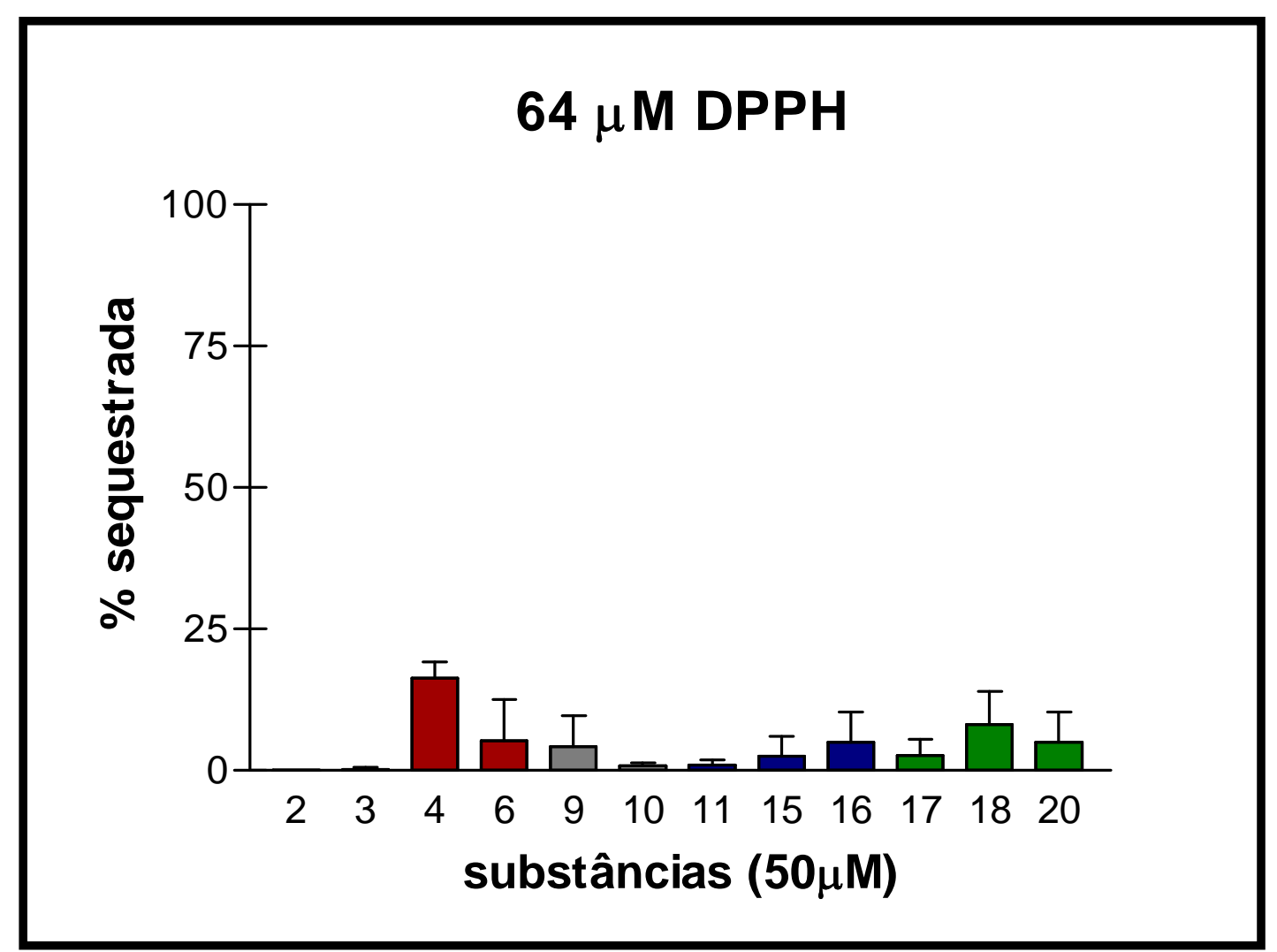

Figura 24. Representação gráfica da atividade doadora de íons hidrogênio ao radical DPPH das lignano-lactonas derivadas da cubebina

Desta forma, podemos aventar que em sistemas livres de células apenas algumas substâncias apresentam discreta capacidade de reagir com radicais livres, não apresentando significativa atividade sequestradora de EROS. 
5 CONCLUSÃO 


\section{Conclusões}

A atividade tripanocida das varias lignano-lactonas avaliadas é promissora, tendo algumas se mostrado mais ativas que o benzonidazol, fármaco usado no tratamento da doença de Chagas;

A indução da produção de $\mathrm{H}_{2} \mathrm{O}_{2}$ e outros peróxidos, a atividade inibitória sobre a enzima gliceraldeído-3-fosfato desidrogenase (GAPDH) de Trypanosoma cruzi, bem como a capacidade de indução da produção de óxido nítrico pelos derivados bioativos são mecanismos que provavelmente não estão envolvidas no modo de ação das substâncias avaliadas;

A inibição da respiração de Trypanosoma cruzi parece estar envolvida na atividade tripanocida das substâncias, podendo contribuir para atividade tripanocida deste grupo de substâncias;

Em sistemas livres de células as substâncias não demonstraram atividade scavenger de radicais livres;

As substâncias inibem a respiração mitocondrial via complexo I, podendo este mecanismo estar relacionado a citotoxicidade;

$>$ De acordo com os resultados de atividade tripanocida a inibição sobre a enzima ferro superóxido dismutase de $T$. cruzi parece ser um dos principais mecanismos envolvido na atividade das substâncias. 
REFERÊNCIAS 


\section{Referências}

ADROHER, F. J; OSUNA, A.; LUPIANEZ, J. A. Differential energetic metabolism during Trypanosoma cruzi differentiation. I. Citrate synthase, NADP-isocitrate dehydrogenase, and succinate dehydrogenase. Archives of biochemistry and biophysics, New York, v. 267, n. 1, p. 252-261, 1988.

ALMEIDA, F. B. Triatomíneos da Amazônia: encontro de três espécies naturalmente infectadas por Trypanosoma semelhante ao cruzi no Estado do Amazonas (Hemiptera, Reduviidae). Acta Amazonica, Manaus, v. 1, n. 1, p. 71-75, 1971.

ANDRADE, S. G. Caracterização de cepas do Trypanosoma cruzi isoladas no Recôncavo Baiano. Revista de Patologia Tropical, Goiânia, v.3, n. 1, p.65-121, 1974.

ANDRADE, S. G. Tentative for grouping different Trypanosoma cruzi strain in some types. Revista do Instituto de Medicina Tropical de São Paulo, São Paulo, v.18, n. 2, p.140-141, 1976.

ANDRADE, S. G.; FIGUEIRA, R. M. Estudo experimental sobre ação terapêutica da droga Ro 7-1051 na infecção por diferentes cepas do Trypanosoma cruzi. Revista do Instituto de Medicina Tropical de São Paulo, São Paulo, v.19, n. 5, p.335-341, 1977.

ANDRADE, S. G.; MAGALHÃES, J. B.; PONTES, A. L. Evaluation of chemotherapy with benznidazole and nifurtimox in mice infected with Trypanosoma cruzi strains of different types. Bulletin of World Health Organization, Geneva, v.63, n. 4, p.721-726, 1985.

ANDRADE, S. G.; RASSI A.; MAGALHÃES, J. B.; FERRIOLI FILHO, F.; LUQUETTI, A. Specific chemotherapy of Chagas disease: a comparison between the response in patients and experimental animals inoculated with the same strain. Transactions of the Royal Society of Tropical Medicine and Hygiene, London, v.86, n. 6, p.624-626, 1992.

APT, W.; AGUILlERA, X.; ARRIBADA, A.; GOMEZ, L.; MILES, M.; WIDMER, G. Epidemiology of Chagas'disease in northern Chile: isozyme profiles in Trypanosoma cruzi from domestic and sylvatic transmission cycles and their association with cardiopathy. American Society of Tropical Medicine and Hygiene, Baltimore, v.37, p.302-307, 1987.

AYRES, D. C.; LOIKE, J. D. Biological and clinical properties of podophyllotoxin and other lignans. In:_Lignans Chemical, Biological and Clinical Properties. Cambridge: Cambridge University Press. 1990. p. 85-112.

BARRETO, M. P.; RIBEIRO, R. D. Reservatórios silvestres do Trypanosoma (Schizotrypanum) cruzi Chagas 1909. Revista do Instituto Adolfo Lutz, São Paulo, v. 39, n. 1, p. 25-36, 1979.

BASTOS, J. K.; ALBUQUERQUE, S.; SILVA, M. L. A. Evaluation of the trypanocidal activity of lignans isolated from the leaves of Zanthoxylum naranjillo. Planta Medica, Stuttgart, v.65, n.1, p.1-4, 1999. 
BASTOS, J. K.; CARVALHO, J. C. T.; SOUZA, G. H. B.; PEDRAZZI, A. H. P.; SARTI, S. J. Anti-inflammatory activity of cubebin, a lignan from the leaves of Zanthoxyllum naranjillo Griseb. Journal of ethnopharmacology, Lausanne, v.75, p.279-82, 2001.

BECKMANN, J. S. The double edge role of nitric oxide in brain function and superoxidemediated injury. Journal of developmental physiology, Oxford, v.15, p.53-9, 1991.

BELTRAN, B.; MATHUR, A.; DUCHEN, M. R.; ERUSALIMSKY, J. D.; MONCADA, S. The effect of nitric oxide on cell respiration: A key to understanding its role in cell survival or death. Proceedings of the National Academy of Sciences of the United States of America, Washington, v. 97, n. 26, p. 14602-7, 2000.

BICE, D. E.; ZELEDÓN, R. Comparison of infectivity of strains of Trypanosoma cruzi. The Journal of parasitology, Lawrence, v.56, n. 4, p.663-670, 1970.

BOCK, M.; GORNERT, R.; HABERKOM, A. Studies with Bay 2502 on animals. Boletín chileno de parasitología, Santiago, v. 24, n. 1, p. 13-19, 1969.

BOTTA, B.; DELlE MONACHE, G.; MISITI, D.; VITALI, A.; ZAPPIA, G. Aryltetralin lignans: chemistry, pharmacology and biotransformations. Current medicinal chemistry, Schiphol v. 8, n. 11, p. 1363-81, 2001.

BRADFORD, M. M. A Rapid and Sensitive Method for the Quantitation of Microgram Quantities of Protein Utilizing the Principles of Protein-Dye Binding. Analytical biochemistry, New York, v.72, p.248-254, 1976.

BRAQUET, P.; GODFROID, J. J. PAF-acether specific binding sites. Design of specific antagonists. Trends in pharmacological sciences, Amsterdam, v. 7, p. 397-403, 1986.

BRENER, Z. Therapeutic activity an criterion of cure on mice experimentally infected with Trypanosoma cruzi. Revista do Instituto de Medicina Tropical de São Paulo, São Paulo, v.4, n. 6, p.389-396, 1962.

BRENER, Z. Comparative studies of different strain of Trypanosoma cruzi. Annals of tropical medicine and parasitology, Liverpool, v.59, p.19-26, 1965.

BRENIERE, S. F.; CARRASCO, R.; REVOLlO, S.; APARICIO, G.; DESJEUX, P.; TIBAYRENC, M. Chagas'disease in Bolivia: Clinical and epidemiological features and zymodeme variability of Trypanosoma cruzi strains isolated from patients. American Society of Tropical Medicine and Hygiene, Baltimore, v.41, n. 5, p.521-529, 1989.

BRINGAUD, F.; RIVIERE, L.; COUSTOU, V. Energy metabolism of trypanosomatids: adaptation to available carbon sources. Molecular and biochemical parasitology, Amsterdam, v. 149, n. 1, p. 1-9, 2006.

BROCKMANN, C.; DIEHL, A.; REHBEIN, K, STRAUSS, H.; SCHMIEDER, P.; KORN, B.; KUHNE, R.; OSCHKINAT, H. The oxidized subunit B8 from human complex I adopts a thioredoxin fold. Structure, London, v. 12, p. 1645-1654, 2004. 
BUCKNER, F. S; VERLINDE, C. L; LA FLAMME, A. C.; VAN VOORHIS, W. C. Efficient technique for screening drugs for activity against Trypanosoma cruzi using parasites expressing beta-galactosidase. Antimicrobial agents and chemotherapy, Washington, v. 40, n. 11, p. 2592-2597, 1996.

CAMPOS, R. F.; GONÇALVES, M. S.; REIS, E. A. G.; REIS, M. G.; ANDRADE, S. Comparative analysis by Polymerase Chain Reaction amplified minicircles of kinetoplast DNA of a stable strain of Trypanosoma cruzi from São Felipe, Bahia, its clones and subclones: possibility of predominance of a principal clone in this area. Memórias do Instituto Oswaldo Cruz, Rio de Janeiro, v.94, n.1, p.23-29, 1999.

CANTIN, A.; LOPEZ-GRESA, M. P.; GONZALEZ, M. C.; MOYA, P.; MIRANDA, M. A.; PRIMO, J.; ROMERO, V.; PERIS, E.; ESTORNELL, E. Novel inhibitors of the mitochondrial respiratory chain: oximes and pyrrolines isolated from Penicillium brevicompactum and synthetic analogues. Journal of agricultural and food chemistry, Washington, v. 53, n. 21, p. 8296-8301, 2005.

CARTHCART, R.; SCHWIERS, E.; AMES, B. Detection of picomole levels of hydroperoxides using a dichlorofluorescein fluorescent assay. Analytical biochemistry, New York, v. 134, p. 111-116, 1983.

CASTELLANI, O.; RIBEIRO L. V.; FERNANDES, J. F. Differenciation of Trypanosoma cruzi in culture. The Journal of protozoology, New York, v.14, n. 3, p.447-451, 1967.

CAZZULO, J. J. Aerobic fermentation of glucose by trypanosomatids. The FASEB journal : official publication of the Federation of American Societies for Experimental Biology, Bethesda, v. 6, n. 13, p. 3153-3161, 1992.

CAZZULO, J. J.; FRANKE DE CAZZULO, B. M.; ENGEL, J. C.; CANNATA, J. J. End products and enzyme levels of aerobic glucose fermentation in trypanosomatids. Molecular and biochemical parasitology, Amsterdam, v. 16, n. 3, p. 329-343, 1985.

CHAGAS, C. Nova tripanozomiaze humana. Memórias do Instituto Oswaldo Cruz, Rio de Janeiro, v.1, n.2, p.159-218, 1909.

CHANCE, B.; WILLANS, G. R. The respiratory chain and oxidative phosphorilation. Advances in enzymology and related subjects of biochemistry, New York, v.17, p.65-134, 1956.

CHARLTON, J. L. Antiviral activity of lignans. Journal of natural products, Cincinnati, v. 61, n. 11, p. 1447-51, 1998.

CHO, M. K.; PARK, J. W.; JANG, Y. P.; KIM, Y. C.; KIM, S. G. Potent inhibition of lipopolysaccharide-inducible nitric oxide synthase expression by dibenzylbutyrolactone lignans through inhibition of I-kappaBalpha phosphorylation and of p65 nuclear translocation in macrophages. International immunopharmacology, Amsterdam, v. 2, n. 1, p. 105-116, 2002. 
CLARK, C. G.; PUNG, O. J. Host specificity of ribosomal DNA variation in sylvatic Trypanosoma cruzi from North America. Molecular and biochemical parasitology, Amsterdam, v. 66, n. 1, p. 175-179, 1994.

COURA, J. R.; CASTRO, S. L. Acritical Review on Chagas Disease Chemotherapy. Memórias do Instituto Oswaldo Cruz, Rio de Janeiro, v. 97, n. 1, p. 3-24, 2002.

CROFT, S. L. The current status of antiparasite chemotherapy. Parasitology, London, v. 114, suppl, p. S3-15, 1997.

D'ALESSANDRO, A.; BARRETO, P.; SARAIVA, N.; BARRETO, M. Epidemiology of Trypanosoma cruzi in the oriental plains of Colombia. American Society of Tropical Medicine and Hygiene, Baltimore, v. 33, n. 6, p. 1084-1095, 1984.

DA SILVA, R; SOUZA, G. H.; DA SILVA, A. A.; DE SOUZA, V. A.; PEREIRA, A. C; ROYO, V. de A.; e SILVA, M. L.; DONATE, P. M., DE MATOS ARAUJO, A. L.; CARVALHO, J. C.; BASTOS, J. K. Synthesis and biological activity evaluation of lignan lactones derived from (-)-cubebin. Bioorganic \& medicinal chemistry letters, Oxford, v. 15, n. 4, p. 1033-7, 2005.

DANTZIG, A.; LALONDE, R. T.; RAMDAYAL, F.; SHEPARD, R. L.; YANAI, K.; ZHANG, M. Cytotoxic responses to aromatic ring and configurational variations in alphaconidendrin, podophyllotoxin, and sikkimotoxin derivatives. Journal of medicinal chemistry, Washington, v. 44, n. 2, p. 180-185, 2001.

DE SOUZA, V. A.; SILVA, R.; PEREIRA, A. C.; ROYO, V. DE A.; SARAIVA, J.; MONTANHEIRO, M.; DE SOUZA, G. H.; DA SILVA FILHO, A. A.; GRANDO, M. D.; DONATE, P. M.; BASTOS, J. K.; ALBUQUERQUE, S.; E SILVA, M. L. Trypanocidal activity of (-)-cubebin derivatives against free amastigote forms of Trypanosoma cruzi. Bioorganic \& medicinal chemistry letters, Oxford, v. 15, n. 2, p. 303-7, 2005.

DEANE, L. M.; DAMASCENO, R. G. Tripanosomídeos de mamíferos da Região Amazônica II tripanosomas de macacos da zona do Salgado, Estado do Pará. Revista do Instituto de Medicina Tropical de São Paulo, São Paulo, v. 3, n. 2, p. 61-70, 1961.

DEANE, L. P. Animal reservoirs of Trypanosoma cruzi in Brasil. Revista brasileira de malariologia e doenças tropicais. Publicações avulsas, Rio de Janeiro, v. 16, n. 1, p. 27-48, 1964.

DEANE, M. P. Significance of polymorphism in Trypanosoma cruzi. In: Congresso Internacional sobre doença de Chagas, 1979, Rio de Janeiro. Anais...Rio De Janeiro: Fundação Oswaldo Cruz, 1979, p.A6-A7.

DEBRABANT, A.; NAKHASI, H. Programmed cell death in trypanosomatids: is it an altruistic mechanism for survival of the fittest? Kinetoplastid biology and disease. London, v. 2, n. 1, p. 7. 2003.

DEGLI ESPOSTI, M. Inhibitors of NADH-ubiquinone reductase: an overview. Biochimica et biophysica acta, Amsterdam, v. 1364, n. 2, p. 222-235, 1998. 
DEGLI ESPOSTI, M.; GHELLI, A.; RATTA, M.; CORTES, D.; ESTORNELL, E. Natural substances (acetogenins) from the family Annonaceae are powerful inhibitors of mitochondrial NADH dehydrogenase (Complex I). The Biochemical journal, London, v. 301, p. 161-167, 1994.

DELANO, W. The PyMol Molecular Graphics System. DeLano Scientific, San Carlos, CA, USA. 2002, Disponível em: http://www.pymol.org > Acesso em: 14 fev. 2007.

DENICOLA, A.; RUBBO, H.; RODRIGUEZ, D.; RADI, R. Peroxynitrite-mediated cytotoxicity to Trypanosoma cruzi. Archives of biochemistry and biophysics, New York, v. 304, p. 279-86, 1993.

DEYAMA, T.; NISHIBE S.; NAKAZAWA Y. Constituents and pharmacological effects of Eucommia and Siberian ginseng. Acta pharmacologica Sinica, Beijing, v. 22, n. 12, p. 105770, 2001.

DIAS, J. C. P.; SILVEIRA, A. C. ; SCHOFIELD, C. J. The Impact of Chagas Disease Control in Latin America - a review. Memórias do Instituto Oswaldo Cruz, Rio de Janeiro, v. 97 n. $5,2002$.

DINIS, T. C.; MADERIA, V. M.; ALMEIDA, L. M. Action of phenolic derivatives (acetaminophen, salicylate, and 5-aminosalicylate) as inhibitors of membrane lipid peroxidation and as peroxyl radical scavengers. Archives of biochemistry and biophysics, New York, v.15, n. 315(1), p.161-169, 1994.

DOCAMPO, R. Recent developments in the chemotherapy of Chagas' disease. Current pharmaceutical design, Schiphol, v. 7, n. 12, p. 1157-1164, 2001.

DOCAMPO, R.; MORENO S. N. Free radical metabolism of antiparasitic agents. Federation proceedings, Washington. V. 45, n. 10, p. 2471-6, 1986

DOCAMPO, R.; MORENO S. N. The metabolism and mode of action of gentian violet. Drug metabolism reviews, New York, v. 22, n. 2-3, p. 161-78, 1990

ESPINOZA, B.; VERA-CRUZ, J. M; GONZALEZ, H.; ORTEGA, E.; HERNANDEZ, R. Genotype and virulence correlation within Mexican stocks of Trypanosoma cruzi isolated from patients. Acta tropica, Amsterdam, v. 70, n. 1, p. 63-72, 1998.

FAIRLAMB, A. H.; CERAMI A. Metabolism and functions of trypanothione in the Kinetoplastida. Annual review of microbiology, Palo Alto, v. 46, n. 695-729, 1992.

FANG, J.; BEATTIE, D. S. Alternative oxidase present in procyclic Trypanosoma brucei may act to lower the mitochondrial production of superoxide. Archives of biochemistry and biophysics, New York, v. 414, n. 2, p. 294-302, 2003.

FARNSWORTH NR, AKERELE O, BINGEL AS, SOEJARTO DD, GUO Z. Medicinal plants in therapy. Bulletin of the World Health Organization, Geneva, v. 63, p. 965-981, 1985. 
FLOHE, L.; JAEGER, T.; PILAWA, S.; SZTAJER, H. Thiol-dependent peroxidases care little about homology-based assignments of function. Redox report, Edinburgh, v. 8, n. 5, p. 256-264, 2003.

FLORA FILHO, R.; ZILBERSTEIN, B. Óxido nítrico: o simples mensageiro percorrendo a complexidade. Metabolismo, síntese e funções. Revista da Associação Médica Brasileira, São Paulo, v. 46, n. 3, p. 265-271, 2000.

FRAIHA NETO, H.; VALENTE, S. A.; VAlENTE, V. C.; PINTO, A. Y. N. Doença de Chagas endêmica na Amazônia. Revista Acad. Med. Pará, Belém, v. 6, p.1-132, 1995.

FUNAYAMA, G. K.; PRADO JÚNIOR, J. C. Estudos dos caracteres de uma amostra boliviana do T.cruzi. Revista da Sociedade Brasileira de Medicina Tropical São Paulo, São Paulo, v.8, n. 2, p.75-81, 1974.

GADELHA, F. R.; MORENO, S. N.; DE SOUZA, W.; CRUZ, F. S.; DOCAMPO, R. The mitochondrion of Trypanosoma cruzi is a target of crystal violet toxicity. Molecular and biochemical parasitology, Amsterdam, v. 34, n. 2, p. 117-26, 1989.

GAZZINELLI, R. T.; OSWALD, I. P.; HIENY, S.; JAMES, L.; SHER, A. The microbicidal activity of interferon-gamma-treated macrophages against Trypanosoma cruzi involves an Larginine-dependent, nitrogen oxide-mediated mechanism inhibitable by interleukin-10 and transforming growth factor-beta. European journal of immunology, Weinheim, v. 22, p. 501-6, 1992.

GIORGIO, S.; BARÃO, S. C.; AUGUSTO, O.; KWEE, J. K. Leishmania amazonensis infection is reduced macrophages treated with guanine ribonucleosides. Acta tropica, Amsterdam, v. 70, p. 119-22, 1998.

GOMES, M. L.; TOLEDO, M. J.; NAKAMURA, C. V.; BITTENCOURT, N. D. E L.; CHIARI, E.; DE ARAUJO, S. M. Trypanosoma cruzi: genetic group with peculiar biochemical and biological behavior. Memórias do Instituto Oswaldo Cruz, Rio de Janeiro,v. 98, n. 5, p. 649-654, 2003.

GREEN, L. C.; WAGNER, D. A.; GLOGOWSKI J.; SHIPPER, P. L.; WISHNOK, J. S.; TANNENBAUM, S. R. Analysis of nitrate, nitrite, and [15N]nitrate in biological fluids. Analytical biochemistry, New York, v. 26, n. 1, p. 131-138, 1982.

HALL, B. F.; JOINER, K. A. Strategies of obligate intracellular parasites for evading host defences. Immunology today, Amsterdam, v. 12, n. (3), p. A22-7, 1991.

HALLIWELL, B.; GUTTERIDGE, J. M. Biologically relevant metal ion-dependent hydroxyl radical generation. An update. FEBS letters, Amsterdam, v. 307, n. 1, p. 108-112, 1992.

HATEFI, Y. The mitochondrial electron transport and oxidative phosphorylation system. Annual review of biochemistry, Palo Alto, v. 54, p. 1015-1069, 1985.

HAUSCHKA, T. S. Persistence of strain-specific behavior in two strains of Trypanosoma cruzi after prolonged transfer through inbred mice. The Journal of parasitology, Lawrence, v. 35, p. 593-599, 1949. 
HELENO, V. C; DA SILVA, R.; PEDERSOLI, S; DE ALBUQUERQUE, S.; BASTOS, J. K.; SILVA, M. L., DONATE, P. M.; da SILVA, G. V.; LOPES, J. L. Detailed 1H and 13C NMR structural assignment of three biologically active lignan lactones. Spectrochimica acta. Part A, Molecular and biomolecular spectroscopy, Kidlington, v. 63, n. 1, p. 234-9, 2006.

HIGUCHI, M. de L.; BENVENUTI, L. A.; MARTINS REIS, M.; METZGER, M. Pathophysiology of the heart in Chagas' disease: current status and new developments. Cardiovascular Research, London v. 60, p. 96-107, 2003.

HOARE, C. A.; WALLACE, F. G. Developmental stages of trypanosomatid flagellates: a new terminology. Nature, London, v. 212, p. 1385-1386, 1966.

HUANG H, CHAN J, WITTNER M, JELICKS LA, MORRIS SA, FACTOR SM, WEISS LM, BRAUNSTEIN VL, BACCHI CJ, YARLETT N, CHANDRA M, SHIRANI J, TANOWITZ HB. Expression of cardiac cytokines and inducible form of nitric oxide synthase (NOS2) in Trypanosoma cruzi-infected mice. Journal of molecular and cellular cardiology, London, v. 31, n. 1, p. 75-88, 1999.

JAMES, S.L. Role of nitric oxide in parasitic infections. Clinical microbiology reviews, Washington, v. 59, p. 533-47, 1995.

KABIRI, M.; STEVERDING, D. Identification of a developmentally regulated iron superoxide dismutase of Trypanosoma brucei. The Biochemical journal, London, v. 360, p. 173-177, 2001.

KASSUYA, C. A.; SILVESTRE, A.; MENEZES-DE-LIMA, O. J. R.; MAROTTA, D. M; REHDER, V. L.; CALIXTO, J. B. Antiinflammatory and antiallodynic actions of the lignan niranthin isolated from Phyllanthus amarus. Evidence for interaction with platelet activating factor receptor. European journal of pharmacology, Amsterdam, v. 546, n. 1-3, p. 182-188, 2006.

KELLY, R. A.; BALLIGAND, J. L.; SMITH, T. Nitric oxide and cardiac function. Circulation research, Baltimore, v. 79, p. 363-80, 1996.

LAINSON, R.; SHAW, J. J.; FRAIHA, H.; MILES, M. A.; DRAPER, C. C. Chagas disease in the Amazon Basin: Trypanosoma cruzi infections in sylvatic mammals, triatomine bugs and man in the State of Pará, north Brasil. Transactions of the Royal Society of Tropical Medicine and Hygiene, London, v. 73, n. 2, p. 193-204, 1979.

LAMBRECH, F. L. Biological variations in trypanosomes and their relation to the epidemiology of Chagas' disease. Revista do Instituto de Medicina Tropical de São Paulo, São Paulo, v. 7, p. 346-352, 1965.

LANDAIS, Y.; ROBIN, J. P.; LEBRUN, A. Ruthenium dioxide in fluoro acid medium: a new agent in the biaryl oxidative couping: application to the synthesis of non phenolic bisbenzocyclooctadiene Lignan Lactones. Tetrahedron, Oxford, v. 47, n. 23, p. 3787-3804, 1991. 
LE TRANT, N.; MESHNICK, S. R.; KITCHENER, K.; EATON, J. W.; CERAMI, A. Ironcontaining superoxide dismutase from Crithidia fasciculata. Purification, characterization, and similarity to Leishmanial and trypanosomal enzymes. The Journal of biological chemistry, Baltimore, v. 258, n. 1, p. 125-130, 1983.

LEID, R. W.; SUQUET, C. M.; TANIGOSHI, L. Oxygen detoxifying enzymes in parasites: a review. Acta Leidensia, Leiden, v. 57, n. 2, p. 107-114, 1989.

LE-SENNE, A.; MUELAS-SERRANO, S.; FERNANDEZ-PORTILLO, C.; ESCARIO, J. A.; GOMEZ-BARRIO, A. Biological characterization of a beta-galactosidase expressing clone of Trypanosoma cruzi CL strain. Memórias do Instituto Oswaldo Cruz, Rio de Janeiro, v. 97, n. 8, p. 1101-5, 2002.

LI, N.; WU, J. L.; HASEGAWA, T.; SAKAI, J.; WANG, L. Y.; KAKUTA, S.; FURUYA, Y.; TOMIDA, A.; TSURUO, T.; ANDO, M. Bioactive dibenzylbutyrolactone and dibenzylbutanediol lignans from Peperômia duclouxii. Journal of Natural Products, Cincinnati, v. 69, n. 2, p. 234-239, 2006.

LOPES, N. P.; CHICARO, P.; KATO, M. J.; ALBUQUERQUE, S.; YOSHIDA, M. Flavonoids and lignans from Virola surinamensis twigs and their in vitro activity against Trypanosoma cruzi. Planta medica. Stuttgart, v. 64, n. 7, p. 667-668, 1998.

LUDWIG, M. L.; METZGER, A. L.; PATTRIDGE, K. A.; STALlinGS, W. C. Manganese superoxide dismutase from Thermus thermophilus. A structural model refined at $1.8 \mathrm{~A}$ resolution. Journal of molecular biology, New York, v. 219, n. 2, p. 335-358, 1991.

LUITGARDS-MOURA, J. F.; VARGAS, A. B.; ALMEIDA, C. E.; MAGNO-ESPERANCA, G.; AGAPITO-SOUZA, R.; FOLLY-RAMOS, E.; COSTA, J.; TSOURIS, P.; ROSAFREITAS, M. G. A Triatoma maculata (Hemiptera, Reduviidae, Triatominae) population from Roraima, Amazon region, Brazil, has some bionomic characteristics of a potential Chagas disease vector. Revista do Instituto de Medicina Tropical de São Paulo, São Paulo, v. 47, n. 3, p. 131-7, 2005.

LUIZE PS, UEDA-NAKAMURA T, FILHO BP, CORTEZ DA, MORGADO-DIAZ JA, DE SOUZA W, NAKAMURA CV. Ultrastructural alterations induced by the neolignan dihydrobenzofuranic eupomatenoid-5 on epimastigote and amastigote forms of Trypanosoma cruzi. Parasitology research, Berlin, v. 100, n. 1, p. 31-37, 2006.

LUQUETTI, A. O; MILES, M. A; RASSI, A; DE REZENDE, J. M; DE SOUZA, A. A; POVOA, M. M.; RODRIGUES, I. Trypanosoma cruzi: zymodemes associated with acute and chronic Chagas' disease in central Brazil. Transactions of the Royal Society of Tropical Medicine and Hygiene, London, v. 80,n. 3, p. 462-70, 1986.

MACEDO, A. M.; MACHADO, C. R.; OLIVEIRA, R. P.; PENA, S. D. Trypanosoma cruzi: genetic structure of populations and relevance of genetic variability to the pathogenesis of chagas disease. Memórias do Instituto Oswaldo Cruz, Rio de Janeiro, v. 99, n. 1, p. 1-12, 2004. 
MACEDO, A. M.; MARTINS, M. S.; CHIARI, E.; PENA, S. D. DNA fingerprinting of Trypanosoma cruzi: a new tool for characterization of strains and clones. Molecular and biochemical parasitology. Amsterdam, v. 55, n. 1-2, p. 147-153, 1992.

MACEDO, A. M.; OLIVEIRA, R. P.; PENA, S. D. J. Chagas disease: role of parasite genetic variation in pathogenesis. Expert reviews in molecular medicine, Cambridge, v. 4, n. 5, p. $1-16,2002$.

MACEDO, A. M.; PENA, S. D. J. Genetic variability of Trypanosoma cruzi: Implications for the pathogenesis of Chagas disease. Parasitology today, Amsterdam, v. 14, n. 3, p. 119-124, 1998.

MAGALHÃES, J. B.; ANDRADE, S. G.; SHERLOCK, Y. Trypanosoma cruzi strains: behavior after passage into authoctonous or foreingn species of triatomine (biological and biochemical patterns). Revista do Instituto de Medicina Tropical de São Paulo, São Paulo, v. 38, n. 1, p. 23-28, 1996.

MARKLUND, S.; MARKLUND, G. Involvement of the superoxide anion radical in the autoxidation of pyrogallol and a convenient assay for superoxide dismutase. European journal of biochemistry, Berlin, v. 47, n. 3, p. 469-474, 1974.

MARTINÉZ-DIAZ, A. A; ESCÁRIO, J. A.; NOGAL-RUIZ, J. J.; GÓMEZ-BARRIO, A. Biological Caracterization of Trypanosoma cruzi Strains. Memórias do Instituto Oswaldo Cruz, Rio de Janeiro, v. 96, n. 1, 2001.

MARTINS, G. A.; CARDOSO, M. A.; ALIBERTI, J. C.; SILVA, J. S. Nitric oxide-induced apoptotic cell death in the acute phase of Trypanosoma cruzi infection in mice. Immunology letters, Amsterdam, v. 63, n. 2, p. 113-120, 1998.

MAYA, J. D.; CASSELS, B. K.; ITURRIAGA-VASQUEZ, P.; FERREIRA, J.; FAUNDEZ, M.; GALANTI, N.; FERREIRA, A.; MORELLO, A. Mode of action of natural and synthetic drugs against Trypanosoma cruzi and their interaction with the mammalian host. Comparative biochemistry and physiology. Part A, Molecular \& integrative physiology. New York, 2006. (no prelo)

MAYA, J. D; MORELLO, A.; REPETTO, Y.; RODRIGUEZ, A.; PUEBLA, P.; CABALLERO, E.; MEDARDE, M.; NUNEZ-VERGARA, L. J.; SQUELLA, J. A.; ORTIZ, M. E.; FUENTEALBA, J.; SAN FELICIANO, A. Trypanosoma cruzi: inhibition of parasite growth and respiration by oxazolo(thiazolo)pyridine derivatives and its relationship to redox potential and lipophilicity. Experimental parasitology, New York, v. 99, n. 1, p. 1-6, 2001.

MILES, M. A.; ARIAS, J. R.; NAIFF, R. D.; SOUZA, A. A.; POVOA, M. M.; LIMA, J. A. $\mathrm{N}$. Vertebrate hosts and vectors of Trypanosoma rangeli in Amazon Basin of Brasil. The American journal of tropical medicine and hygiene, Baltimore. v. 32, n. 6, p. 1251-1259, 1983.

MILES, M. A.; CEDIllos, R. A.; POVOA, M. M.; SOUZA, A. A.; DE PRATA, A.; MACEDO, V. Do radically dissimilar Trypanosoma cruzi strains (zymodemes) cause Venezuela and Brazilian forms of Chagas'disease? Lancet, London, v.1, n. 8234, p. 13381340, 1981. 
MILES, M. A.; LANHAM, S. M.; POVOA, M. Further enzymic characters of Trypanosoma cruzi in their evaluation for strain identification. Transactions of the Royal Society of Tropical Medicine and Hygiene, London, v.74, n. 2, p. 221-237, 1980.

MILES, M. A.; TOYE, P. J.; OSWALD, S. C.; GODFREY, D. G. The identification by isoenzyme patterns of two distinct strain-groups of Trypanosoma cruzi, circulating independently in a rural area of Brazil. Transactions of the Royal Society of Tropical Medicine and Hygiene. London, v. 71, n. 3, p. 217-225, 1977.

MOREL, C. M.; LAZDINS, J. Chagas disease. Nature Reviews Microbiology, London, v. 1, n. 1, p. 14-15, 2003.

MOREL, C.; CHIARI, E.; CAMARGO, E. P.; MATTEI, D.M.; ROMANHA, A. J.; SIMPSON, L. Strains and clones of Trypanosoma cruzi can be characterized by pattern of restriction endonuclease products of kinetoplast DNA minicircles. Proceedings of the National Academy of Sciences of the United States of America, Washington, v. 77, n. 11, p. 6810-6814, 1980.

MUELAS, S.; SUAREZ, M.; PEREZ, R.; RODRIGUEZ, H.; OCHOA, C.; ESCARIO, J. A.; GOMEZ-BARRIO, A. In vitro and in vivo assays of 3,5-disubstituted-tetrahydro-2H-1,3,5thiadiazin-2-thione derivatives against Trypanosoma cruzi. Memórias do Instituto Oswaldo Cruz, Rio de Janeiro, v. 97, n. 2, p. 269-272, 2002.

NAIFF, M. F.; NAIFF, R. D.; BARRET, T. V. Vetores selváticos de doença de Chagas na área urbana de Manaus (AM): atividade de vôo nas estações secas e chuvosas. Revista da Sociedade Brasileira de Medicina Tropical São Paulo, São Paulo, v. 31, n. 1, p. 103-105, 1998.

NAVARRO, M. V. A. S. Estudos estruturais de enzimas anti-oxidantes e glicolíticas de parasitas tropicais: Fe-superóxido dismutase e enolase. 2006. 220f. Tese (Doutorado em Cièncias)- Instituto de física de São Carlos, Universaidade de São Paulo, São Carlos, 2006.

NORVAL, M. Mechanism of persistence of rubella vírus in LLC-MK2 cells. The Journal of general virology, London, v. 43, p. 289-298, 1979.

NUSSENZWEIG, V.; SONNTAG, R.; BIANCALANA, A.; FREITAS, J. L. P.; NUSSENZWEIG, R. S.; KLOETZEL, J. Ação de corantes trifenilmetânicos sobre o Trypanosoma cruzi in vitro. Emprego da violeta-de-genciana na profilaxia da transmissão da moléstia de chagas por transfusão de sangue. Hospital, Rio de Janeiro, v.44, n. 6, p.731-744, 1953.

PEDERSEN, P. L.; GREENAWALT, J. W.; REYNAFARJE, B.; HULLIHEN, J.; DECKER, G. L.; SOPER, J. W.; Bustamente, E. Preparation and characterization of mitochondria and submitochondrial particles of rat liver and liver-derived tissues. Methods in cell biology, New York v. 20, p. 411-481, 1978.

PEDROSA, R. C.; DE BEM, A. F.; LOCATELLI, C.; PEDROSA, R. C.; GEREMIAS, R.; WILHELM FILHO, D. Time-dependent oxidative stress caused by benznidazole. Redox report : communications in free radical research, Edinburgh, v.6, n.4, p. 265-270, 2001. 
PEREIRA DA SILVA, L. H.; NUSSENZWEIG, V. Sobre uma cepa de Trypanosoma cruzi altamente virulenta para o camundongo branco. Folia clinica et biológica, São Paulo. v. 20, n. 3, p. 191-208, 1953.

PETRAY, P.; ROTTENBERG, M. E.; GRINSTEIN, S.; ORN, A. Release of nitric oxide during the experimental infection with Trypanosoma cruzi. Parasite immunology, Oxford, v. 16, p. 193-9, 1994.

PIACENZA L, IRIGOIN F, ALVAREZ MN, PELUFFO G, TAYLOR MC, KELLY JM, WILKINSON SR, RADI R. Mitochondrial superoxide radicals mediate programmed cell death in Trypanosoma cruzi: cytoprotective action of mitochondrial Fe-superoxide dismutase overexpression. The Biochemical journal, London, 2006. (no prelo)

PIACENZA, L.; PELUFFO, G.; RADI, R. L-arginine-dependent suppression of apoptosis in Trypanosoma cruzi: contribution of the nitric oxide and polyamine pathways. Proceedings of the National Academy of Sciences of the United States of America, Washington, v. 98, n. 13, p. 7301-7306, 2001.

PIAGGIO E.; SANCEAU J.; REVELLI S.; BOTTASSO O.; WIETZERBIN J.; SERRA E. Trypanocidal drug benznidazole impairs lipopolysaccharide induction of macrophage nitric oxide synthase gene transcription through inhibition of NF-kappaB activation. The Journal of immunology:official journal of the American Association of Immunologists, Baltimore, v. 167, n. 6, p. 3422-3426, 2001.

PICCINELLI, A. L.; MAHMOOD, N.; MORA, G.; POVEDA, L.; De SIMONE, F.; RASTRELLI, L. Anti-HIV activity of dibenzylbutyrolactone-type lignans from Phenax species endemic in Costa Rica. The Journal of pharmacy and pharmacology, London, v. 57, n. 9, p. 1109-15, 2005.

PRATA, A. Clinical and epidemiological aspects of Chagas disease. The Lancet infectious diseases, New York, v. 1, p. 92-100, 2001.

RADI, R.; BECKMANN, J.S.; BUSH, K.M.; FREEMAN, B.A. Peroxynitrite-induced membrane lipid oxidation: the cytotoxic potential of superoxide and nitric oxide. Archives of biochemistry and biophysics, New York, v. 288, p. 481-7, 1991.

RAETHER, W.; HANEL, H. Nitroheterocyclic drugs with broad spectrum activity. Parasitol Research, Berlin, v. 90, supp 1, p. S19-39, 2003.

RAMIREZ, L. E.; LAGES-SILVA, E.; PIANETTI, G. M.; RABELO, R. M.; BORDIN, J. O.; MORAES-SOUZA, H. Prevention of transfusion-associated Chagas' disease by sterilization of Trypanosoma cruzi-infected blood with gentian violet, ascorbic acid, and light. Transfusion, Philadelphia, v. 35, n. 3, p. 226-230, 1995.

REVElli, S.; LE PAGE, C.; PIAGGIO, E.; WIETZERBIN, J.; BOTTASSO, O. Benznidazole, a drug employed in the treatment of Chagas' disease, down-regulates the synthesis of nitrite and cytokines by murine stimulated macrophages. Clinical and experimental immunology, Oxford, v. 118, n. 2, p. 271-277, 1999. 
REVOLLO, S.; OURY, B.; LAURENT, J. P.; BARNABE, C.; QUESNEY, V.; CARRIERE, V.; NOEL, S.; TIBAYRENC, M. Trypanosoma cruzi: impact of clonal evolution of the parasite on its biological and medical properties. Experimental parasitology, New York, v. 89, n. 1, p. 30-39, 1998.

RIBEIRO, R. D.; BELDA NETO, F. M. Estudo morfológico de subamostras do Trypanosoma cruzi. ii - estudo micrométrico de tripomastigotas sanguícolas das subamostras Bolívia SN e Bolívia SD. In: Jornada Farmacêutica, 30, 1983. Resumos...Araraquara: Faculdade de Ciências Farmacêuticas, 1983, p.31.

RIBEIRO, R. D.; FERRIOLLI FILHO, F.; BELDA NETO, F. M. comportamento de subamostras do Trypanosoma cruzi em hospedeiros vertebrados e invertebrados. Revista brasileira de biologia, Rio de Janeiro v.42, n.1, p.51-4, 1982.

RIBEIRO, R. D.; LOPES, R. A.; CARMO, T. A.; RISSATO, E.; GARCIA, T. A. Índice de cura de camundongos tratados com nifurtimox e benzonidazol na doença de Chagas. Revista de Ciências Farmacêuticas São Paulo, São Paulo, v. 10, p. 71-76, 1988.

RICHLE, R. Chemotherapy of experimental acute Chagas disease in mice: benefical effect of Ro- 71051 on parasitemia and tissue parasitism. Le Progrés médical, Paris, v. 101, p. 282, 1973.

RIMANDO, A. M.; PEZZUTO, J. M.; FARNSWORTH, N. R.; SANTISUK, T.; REUTRAKUL, V.; KAWANISHI, K. New lignans from Anogeissus acuminata with HIV-1 reverse transcriptase inhibitory activity. Journal of natural products, Cincinnati, v. 57, n. 7, p. 896-904, 1994.

ROBAK, J.; GRYGLEWSKI, R. J. Flavonoids are scavengers of superoxide Anion. Biochemical pharmacology, Oxford, v. 37, n. 5, p. 837-841, 1988.

RODRIGUES, C. I.; SOUZA, A. A.; TERCEROS, R.; VALENTE, S. Doença de Chagas na Amazonia: I Registo de oito casos.autóctones em Macapa. Revista da Sociedade Brasileira de Medicina Tropical São Paulo, São Paulo, v. 21, n. 4, p. 193-197, 1988.

RODRIGUES, E. R. Estudos pré-clínicos de possíveis efeitos adversos da Cubebina. 2002. Tese (Doutorado) - Faculdade de Ciências Farmacêuticas de Ribeirão Preto, Universidade de São Paulo, Ribeirão Preto, 2002.

RODRIGUEZ-CIRIA, M.; SANZ, A. M.; YUNTA, M. J.; GOMEZ-CONTRERAS, F.; NAVARRO, P.; SANCHEZ-MORENO, M.; BOUTALEB-CHARKI, S.; OSUNA, A.; CASTINEIRAS, A.; PARDO, M.; CANO, C.; CAMPAYO, L. 1,4Bis(alkylamino)benzo[g]phthalazines able to form dinuclear complexes of $\mathrm{Cu}$ (II) which as free ligands behave as SOD inhibitors and show efficient in vitro activity against Trypanosoma cruzi. Bioorganic and medicinal chemistry, Oxford, V. 15, n. 5, p. 2081-91, 2007

ROMANHA, A. J.; BRENER, Z. Trypanosoma cruzi isoenzyme pattern as an epidemiological tool. Memórias do Instituto Oswaldo Cruz, Rio de Janeiro, v. 83, suppl 1, p. 383-386, 1988. 
ROVAI LE, AOKI A, GEREZ DE BURGOS NM, BLANCO A Effect of gossypol on trypomastigotes and amastigotes of Trypanosoma cruzi. The Journal of protozoology, New York, v. 37, n. 4, p. 280-286, 1990.

SALEEM, M.; KIM, H. J.; ALIC, M. S.; LEE, Y. S. An update on bioactive plant lignans. Natural Product Reports, London, v. 22, n. 6, p. 696-716, 2005.

SATELLITE MEETING. Recommendations from a satellite meeting. Memórias do Instituto Oswaldo Cruz, Rio de Janeiro, v. 94 s. 1, p.429-432, 1999.

SEPULVEDA-BOZA, S.; CASSELS, B. K. Plant metabolites active against Trypanosoma cruzi. Planta Medica, Stuttgart, v. 62, n. 2, p. 98-105, 1996.

SHEN, T. Y.; HWANG, S. B; CHANG, M. N.; DOEBBER, T. W.; LAM, M. H.; W. U., M. S.; WANG, X.; HAN, G. Q; LI, R. Z. Characterization of a platelet-activating factor receptor antagonist isolated from haifenteng (Piper futokadsura): specific inhibition of in vitro and in vivo platelet-activating factor-induced effects. Proceedings of the National Academy of Sciences of the United States of América, Washington, v. 82, n. 3, p. 672-6, 1985.

SHERLOCK, I. A; CARCAVALLO, R. U.; GIRÓN, I. G. List of natural and experimental flagellate infections in serveral triatominae species. In: Atlas dos vetores da doença de Chagas nas Américas. Rio de Janeiro: Fiocruz, v. 1, cap. 8, 1997.

SIEUWERTS, A. M.; KLIJN, J. G.; PETERS, H. A.; FOEKENS, J. A. The MTT tetrazolium salt assay scrutinized: how to use this assay reliably to measure metabolic activity of cell cultures in vitro for the assessment of growth characteristics, IC-50-values and cell survival. European journal of clinical chemistry and clinical biochemistry : journal of the Forum of European Clinical Chemistry Societies, Berlin, v. 33, n. 11, p. 813-823, 1995.

SILVA, C. H. P.; SANCHES, S. M.; TAFT, C. A. A molecular modeling and QSAR study of suppressors of the growth of Trypanosoma cruzi epimastigotes. Journal of molecular graphics and modelling, New York v. 23, n. 1, p. 89-97, 2004.

SILVEIRA, A. C.; REZENDE, D. F. Epidemiologia e controle da transmissão vetorial da doença de Chagas no Brasil. Revista da Sociedade Brasileira de Medicina Tropical São Paulo, São Paulo, v. 27, supl 3, p. 11-22, 1994.

SILVEIRA, A. C.; VINHAES, M. C. Elimination of vector-borne transmission of Chagas disease. Memórias do Instituto Oswaldo Cruz, Rio de Janeiro, v. 94, suppl. 1, p. 405-411, 1999.

SOUTO RP, ZINGALES B. Sensitive detection and strain classification of Trypanosoma cruzi by amplification of a ribosomal RNA sequence. Molecular and biochemical parasitology, Amsterdam, v. 62, n. 1, p. 45-52, 1993.

SOUTO, R.; FERNANDES, O.; MACEDO, A. M.; CAMPBELL, D.; ZINGALES B. DNA markers define two major phylogenetic lineages of Trypanosoma cruzi. Molecular and biochemical parasitology, Amsterdam, v. 83, n. 2, p. 141-152, 1996. 
SOUZA, D. H. F.; GARRAT, R. C.; ARAÚJO, A. P. U.; GUIMARÃES, B. G.; JESUS, W. D. P.; MICHELS, P. A. M.; HANNAERT, V.; OLIVA, G. Trypanosoma cruzi glycosomal glyceraldehyde-3-phosphate dehydrogenase: struture, catalytic mechanism and targeted inhibitor design. FEBS letters, Amsterdam, v. 424, p. 131-135, 1998.

SOUZA, G. H.; DA SILVA FILHO, A. A.; DE SOUZA, V. A.; PEREIRA, A. C.; ROYO, V. de A; E SILVA, M. L.; DA SILVA, R.; DONATE, P. M.; CARVALHO, J. C.; BASTOS, J. $\mathrm{K}$. Analgesic and anti-inflammatory activities evaluation of (-)-O-acetyl, (-)-O-methyl, (-)-Odimethylethylamine cubebin and their preparation from (-)-cubebin. Il Fármaco, Pavia, v. 59, n. 1, p. 55-61, 2004.

SPARTAN ’06 FULL. Tutorial and User’s Guide, Wavefunction, Inc., USA, 2006.

STOPPANI, A. O; DOCAMPO, R.; DE BOISO, J. F.; FRASCH, A. C. Effect of inhibitors of electron transport and oxidative phosphorylation on Trypanosoma cruzi respiration and growth. Molecular and biochemical parasitology, Amsterdam, v. 2, n. 1, p. 3-21, 1980.

SUJA, K. P.; JAYALEKSHMY, A.; ARUMUGHAN, C. Free radical scavenging behavior of antioxidant compounds of sesame (sesamum indicum L.) in DPPH(*) system. Journal of agricultural and food chemistry, Washington, v. 25, n. 52(4), p. 912-915, 2004.

TALIAFERRO, W. H.; PIZZI, T. Connective tissue reactions in normal and immunized mice to a reticulotropic strain of Trypanosoma cruzi. The Journal of infectious diseases, Chicago., v. 96, p. 199-226; 1955.

TEIXEIRA, A. R. L.; MONTEIRO, P. S.; REBELO, J. M.; ARGANAARAZ, E. R.; VIEIRA, D.; LAURIA-PIRES, L.; NASCIMENTO, R.; VEXENAT, C. A.; SILVA, A. R.; AULT, S. K.; COSTA, J. M. Emerging Chagas Disease: trophic network and cycle of transmission of Trypanosoma cruzi from Palm Trees in Amazon. Emerging infectious diseases, Atlanta, v. 7, n. 1, p. 100-112, 2001.

TENGAN, C. H.; KIYOMOTO, B. H.; ROCHA, M. S.; TAVARES, V. L.; GABBAI, A. A.; MORAES, C. T. Mitochondrial encephalomyopathy and hypoparathyroidism associated with a duplication and a deletion of mitochondrial deoxyribonucleic acid. The Journal of clinical endocrinology and metabolism, Springfield. v. 83, n. 1, p. 125-9, 1998.

THOMAS, S. M., MCPHEE, D. G. Crystal violet: a direct- acting frameshift mutagen whose mutagenicity is enhanced by mammalian metabolism. Mutation research, Amsterdam, n. 140, p. 165-167, 1984.

TIBAYRENC, M. Population genetics of parasitic protozoa and other microorganisms. Advances in parasitology, London, v. 36, p. 47-115, 1995.

TIBAYRENC, M.; AYALA, F. J. High correlation between isoenzyme classification and kinetoplast DNA variability in Trypanosoma cruzi. Comptes rendus de l'Académie des sciences III, Paris; v. 304, n. 4, p. 89-92,1987. 
TIBAYRENC, M.; KJELLBERG, F.; AYALA, F. J. A clonal theory of parasitic protozoa: the population structures of Entamoeba, Giardia, Leishmania, Naegleria, Plasmodium, Trichomonas, and Trypanosoma and their medical and taxonomical consequences. Proceedings of the National Academy of Sciences of the United States of America, Washington, v. 87, n. 7, p. 2414-2418, 1990.

TIELENS, A. G. M.; VAN HELLEMOND, J. J. Differences in Energy Metabolism Between Trypanosomatidae. Parasitology Today, Amsterdam v. 14, p. 265-271, 1998.

TURRENS, J. F. Oxidative stress and antioxidant defenses: a target for the treatment of diseases caused by parasitic protozoa. Molecular aspects of medicine, Oxford, v. 25, n. 1-2, p. 211-20, 2004.

TURRENS, J. F.; MCCORD, J. M. The iron-containing superoxide dismutases of trypanosomatidae. Free radical biology and medicine, New York,. v. 40, n. 2, p. 193-5, 2006.

UDINO, L.; ABAUL, J.; BOURGEOIS, P.; GORRICHON, L.; DURAN, H.; ZEDDE, C. Lignans from the Seeds of Hernanda sonora Planta Medica, Stuttgart, v. 65, n. 3, p. 279280, 1999.

VEGA, C.; ROLON, M.; MARTINEZ-FERNANDEZ, A. R.; ESCARIO, J. A.; GOMEZBARRIO, A. A new pharmacological screening assay with Trypanosoma cruzi epimastigotes expressing beta-galactosidase. Parasitology research, Berlin, v. 95, n. 4, p. 296-298, 2005.

VERDONK, M. L.; COLE, J. C.; HARTSHORN, M. J.; MURRAY, C. W.; TAYLO, R R. D., Improved protein-ligand docking using GOLD. Proteins, New York, v. 52, n. 4, p. 609-623, 2003.

VESPA, G. N. R.; CUNHA, F. Q.; SILVA, J. S. Nitric oxide is involved in control of Trypanosoma cruzi-induced parasitemia and directly kills the parasite in vitro. Infection and immunity, Washington., v. 62, p. 5177-82, 1994.

VIEIRA, P.C.; MAFEZOLI, J.; PUPO, M.T.; FERNANDES, J. B.; SILVA, M.F.G.F.; ALBUQUERQUE, S.; OLIVA, G.; PAVÃO,. F. Strategies for the isolation and identification of trypanocidal compounds from the Rutales. Pure and applied chemistry. Chimie pure et appliquée, London, v. 73, p. 617-622, 2001.

WHO. Tropical disease research (TDR), World Health Organization, 2005, disponível em: http://www.who.int/tdr/publications/publications/pdf/pr17/chagas.pdf > Acesso em: 7 mar. 2007.

ZINGALES, B.; SOUTO, R. P.; MANGIA, R. H.; LISBOA, C. V.; CAMPBELL, D. A.; COURA, J. R.; JANSONS; A. FERNANDES, O. Molecular epidemiology of American trypanosomiasis in Brazil based on dimorphism of rRNA and mini-exon gene sequences. International journal for parasitology, Oxford, v .28, n. 1, p. 105-112, 1998. 